NBSIR $74-512$

\title{
The Proof Testing of Porcelain Insulators and the Application of Acoustic Emission
}

A. G. Evans, S. M. Wiederhorn, M. Linzer and E. R. Fuller, Jr.

Inorganic Materials Division

Institute for Materials Research

National Bureau of Standards

Washington, D. C. 20234

June 1974

Final Report

Prepared for

Naval Civil Engineering Laboratory

Port Hueneme, California 93043 
Evans, A. G., Wlederhorn, S. M., Linzer, M., Fuller, E. R., Jr., Proof testing of porcelain insulators and application of acoustic emlssion, Am. Ceram. Soc. Bull. 54, No. 6, 576-581 (June 1975).

313 . NBSIR $74-512(R)$ 


\section{THE PROOF TESTING OF PORCELAIN INSULATORS AND THE APPLICATION OF ACOUSTIC EMISSION}

A. G. Evans, S. M. Wiederhorn, M. Linzer and E. R. Fuller, Jr.

Inorganic Materials Division

Institute for Materials Research

National Bureau of Standards

Washington, D. C. 20234

June 1974

Final Report

To be published in the Journal of The American Ceramic Society

Prepared for

Naval Civil Engineering Laboratory

Port Hueneme, California 93043

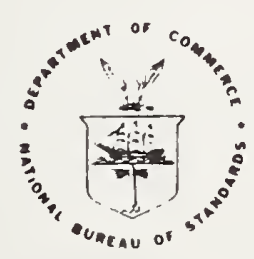

U. S. DEPARTMENT OF COMMERCE, Frederick B. Dent, Secretary 


\section{ABSTRACT}

An investigation of proof testing has been conducted on large cone and post porcelain insulators. The cone configuration was found to be unsuitable for overload proof testing to the loads needed for effective lifetime predictions. The only merit of subjecting this configuration to a proof test is the assurance of no immediate macrocracking during installation. This is achieved by testing to a load marginally larger than the service load. Conversely, the post configuration was found to exhibit the basic prerequisites for effective proof testing; but detailed stress analysis of this system is needed before specific proof testing procedures can be recommended. Finally, acoustic emission measurements were found to be a major asset for monitoring both macrocracking events and stress development during the proof tests. 


\section{INTRODUCTION}

Macrocrack formation has been observed by the Navy in a number of the porcelain base insulators used to support large radio communications towers. These cracks do not, per se, impose a severe structural limitation because the primary stresses in the insulator are compressive. But, in the presence of the high voltage R.F. fields, the heat generated around the cracks may lead to structural degradation. Hence, towers containing cracked insulators are shut down. The prevention of macrocrack formation in porcelain base insulators is thus a primary requirement, if continuous operation (of the radio towers) is to be achieved.

One approach that can be used to prevent in-service macrocrack formation in ceramic components is overload proof testing. This is an evaluation procedure which subjects the insulator to a load greater than the service load. Then, if the insulator survives the proof test, it should satisfy engineering requirements of service load and lifetime. [1] The proof test condition for components made of porcelain must take into account the subcritical crack growth that occurs in this material due to moisture in the environment. [2] Subcritical crack growth leads to a time dependence of the strength, and the time to failure is determined by the time necessary for a crack to grow from a subcritical to a critical size. [1] A mathematical framework for the proof testing of components made of materials that exhibit subcritical crack growth indicates that the important parameters in proof testing are: $[1,3,4]$ the proof test load, the test environment and the loading cycle. In addition, for compressive proof testing, a failure criterion must be specified, because crack size criticality does not lead to complete fracture.

In this paper, the proof test approach is applied to two types of porcelain base insulators commonly used to support radio towers. The variables of the study are loading rate and proof test load. Particular emphasis is placed on the use of acoustic emission to detect crack growth and as an aid in the formulation of a failure criterion. 
The two types of insulators studied are shown in Figures 1 and 2. the bell-shaped "cone" insulators (Figure 1) were approximately one meter in height and one meter in diameter at the base. They were hollow, with a wall thichness at the base of approximately $0.08 \mathrm{~m}$. The ends of the insulators were enclosed by steel end-caps, attached by Portland cement. The bottom bearing surface and the side surfaces of the porcelain were glazed, but the top bearing surface was not. The insulator was designed for a maximum compressive force of $13.5 \mathrm{MN}$.

The "post" insulators (Fig. 2) were solid and cylindrical in shape, with circumferential skirts for improved electrical insulation. They too had steel caps at the top and bottom, attached by Portland cement. These insulators were designed for a maximum compressive force of $4.5 \mathrm{MN}$.

Tests were conducted using the 50 MN NBS test facility. A universal joint was placed at the top of each insulator to reduce loading eccentricities, and strain gauges were placed around the circumference to check on the uniformity. Loading and unloading times were varied from several seconds to approximately 1 hour. Tests were conducted in air (approximately 50 percent relative humidity). A total of four insulators were tested, two of each configuration.

The proof test load was established from a design diagram, developed earlier from subcritical crack growth studies on porcelain specimens cut from a similar cone insulator. [2] The design diagram (Fig. 3) gives a logarithmic plot of the minimum expected time to failure, $t_{\text {min' }}$ versus the service stress, $\sigma_{a}$. Each straight line on this figure relates $\sigma_{a}$ to $t_{\min }$ for a predetermined value of the proof ratio, i.e. the ratio of the proof stress $\left(\sigma_{p}\right)$ to the service stress. Once a tentative determination is made of both the service stress and the minimum acceptable time to failure, the proof ratio can be determined form Fig. 3. For the cone insulators the maximum tensile stress at the service load (4.5 MN), as

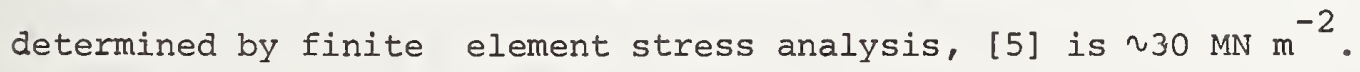

$\overline{1 \mathrm{MN}}=2.4 \times 10^{5} \mathrm{lbf}$. 
Therefore, for a minimum service lifetime of 40 years, the requisite proof ratio obtained from Fig. 3 is 2.5, giving a proof load of $11.3 \mathrm{MN}$. As noted in the preceding section, insulator "failure" has essentially occurred when macrocracks develop that are large enough to result in excessive heat generation, at the crack, during service. Since these cracks are mechanically stable and often do not appear at the external surface, a nondestructive means of detecting their presence was required. The two detection methods used in this study were ultrasonic pulse echo and acoustic emission. Each of the insulators was inspected ultrasonically ${ }^{*}$ before and after each load cycle to detect the presence of macrocracks. Acoustic emission transducers capable of detecting signals emitted in a frequency range close to $180 \mathrm{kHz}$ were attached to the insulators and were monitored continuously during the test. Ultrasonic transducers were also attached to some of the insulators during the tests and were periodically excited in an attempt to detect cracking, and hence, to relate crack formation to the load level and the acoustic emission rate. After testing, the insulators were sectioned to confirm predictions made from acoustic emission observations and ultrasonic inspection, and to determine the source of fracture.

\section{EXPERIMENTAL RESULTS}

\subsection{Cone Insulator Tests}

a) First Insulator

The first of two cone insulators was tested to three different proof levels, 7, 11 and $16 \mathrm{MN}$, in order to assess the general features of the structural and acoustic emission response. The initial loading rate was rapid ( $0.45 \mathrm{MN} / \mathrm{min}$ ) up to approximately 60 percent of the proof load, and then reduced to $\sim 0.14 \mathrm{MN} / \mathrm{min}$ for the final load increment. The insulator was unloaded at $\sim 0.9 \mathrm{MN} / \mathrm{min}$. Strain gauges located at

\footnotetext{
*All ultrasonic testing reported in this paper was performed by Naval Research Laboratory personnel under the direction of $\mathrm{s}$. Hart. 
intervals of 120 degrees around the circumference at the mid-height indicated that the strains were within 3 percent of the average strain.

In all three cycles the acoustic emission rate increased during loading, decayed during holding periods, but increased again as the load was reduced. The increase on unloading was minimal for the $7 \mathrm{MN}$ test cycle, but rather substantial for the other two cycles, as depicted in Fig. 4 for the $11 \mathrm{MN}$ cycle. For this latter cycle (Fig. 4), the acoustic emission rate increased slowly between 11 MN and I MN (from $10^{3}$ to $3 \times 10^{3}$ counts/s); but below $1 \mathrm{MN}$, the rate increased rapidly, and reached a maximum of $3 \times 10^{4}$ counts/s at zero load. This order of magnitude increase in the acoustic emission rate probably corresponded to the growth of a large internal crack, which was identified after the proof test by ultrasonic inspection, and later by sectioning. Visual inspection after sectioning showed that the crack initiated at the bearing surface between the porcelain and the metal end cap, and propagated approximately $0.15 \mathrm{~m}$ below the lip of the end cap and approximately one-third of the way around the circumference.

Crack formation and acoustic emission were even more apparent during the proof test cycle to $16 \mathrm{MN}$ (which was $2.5 \mathrm{MN}$ above the compressive strength reported by the manufacturer). As the load was increased above $13 \mathrm{MN}$ peaks of continuous acoustic emission were obtained (i.e., an acoustic emission rate $>10^{5}$ counts/s); similar, but more extensive, peaks were noted when the insulator was unloaded. These emission peaks probably corresponded to the growth of large cracks, which were identified after the test by inspection. Visual inspection indicated that the cracks initiated from the porcelain/cement bearing surfaces at the top and bottom end caps. Cracks from the lower end cap frequently appeared on the external surface.

The strain gauge measurements and all of the mechanical testing instrumentation were performed by personnel from the Engineering Mechanics Section at NBS. 
The topology of the cracks was examined by ultrasonic and visual inspection after testing. Two principal types of crack were formed: laminar cracks that grew from the top and bottom end caps roughly parallel to the exterior surface, and orthogonal cracks that grew through the insulator wall perpendicular to the exterior surface. An example of a laminar crack that emerged at the exterior surface is shown in Fig. 5. By sectioning the insulator we were able to show that this type of crack grew from the sloped bearing surfaces at the base and top of the insulator (Fig. 6). The rough surfaces of the laminar cracks served as nucleating sites for the longitudinal through cracks, shown in Fig. 7.

b) Second Insulator

The proof test of the second cone insulator was designed in an attempt to establish a specific proof test procedure that would provide an effective lifetime assurance. Two load cycles were used, differing only in the rate of load application; the maximum load in both cases being $7 \mathrm{MN}$. In the first cycle, the loading and unloading rates were $0.14 \mathrm{MN} / \mathrm{min}$. In the second cycle, the loading rate was $0.9 \mathrm{MN} / \mathrm{min}$ and the average unloading rate was approximately $7 \mathrm{MN} / \mathrm{min}$. Ultrasonic transducers were attached to the external surface of the insulator to detect the growth of cracks during the test. Strain gauges located 120 degrees apart around the circumference at the mid height were within 10 percent of the average strain.

\footnotetext{
*ther crack forms were observed in isolated cases; visual observation identified one circumferential crack orthogonal to the applied load, and ultrasonic inspection indicated the presence of many small internal cracks after rapid unloading.
} 
The acoustic emission rate slowly increased as the insulator was loaded and further increased as the insulator was unloaded (Fig. 8). A large acoustic emission peak was observed at 9 MN during unloading. This peak was shown to correspond to macrocrack formation by an ultrasonic inspection during the proof test, in which the back surface reflection under one of the transducers slowly disappeared and was replaced by a reflection approximately one-half the distance between the interior and exterior surfaces. Additional ultrasonic inspection after the proof test confirmed the existence of this crack, which extended one-third of the way around the circumference and approximately $0.15 \mathrm{~m}$ below the upper end cap. The second proof test cycle resulted in saturation level acoustic emission rates $\left(>10^{5}\right.$ counts/s) when the specimen was unloaded. Ultrasonic inspection of the cone insulator after testing detected no additional large cracks, but many small reflections were detected suggesting the nucleation and growth of many small cracks throughout the body of the insulator.

\subsection{Post Insulator Tests}

\section{a) First Insulator}

The first of the two post insulators was tested to several loads, $3,4.5,5.4,6.3$ and $8 \mathrm{MN}$ in order to assess the basic structural and acoustic emission response of the configuration. Axial strains measured by four strain gauges placed 90 degrees apart around the circumference at the mid height of the insulator were within 7 percent of the average load at $3 \mathrm{MN}$. In the first cycle, the insulator was loaded to $3 \mathrm{MN}$ at a rate of $0.14 \mathrm{MN} / \mathrm{min}$ and unloaded at a rate of $0.16 \mathrm{MN} / \mathrm{min}$. A gradual increase in the acoustic emission rate accompanied the load increase (Fig. 9) and a decrease was observed when held at the proof 1oad. But, the acoustic emission rate decreased during unloading (Fig.9), a behavior which differs from that observed on the cone insulators. Ultrasonic examination after the proof test gave no indication of macrocrack formation. 
The acoustic emission behavior at proof test loads of 4.5 and $5.4 \mathrm{MN}$ was in general ${ }^{*}$ similar to that observed for the test at $3 \mathrm{MN}$. The acoustic emission level increased as the load increased, but decreased both during the holding and unloading periods. During the proof test to $6.3 \mathrm{MN}$, acoustic emission peaks were observed during loading and unloading, and subsequent visual inspection showed that some spalling occurred at the lower insulator skirts. Finally, when the insuiator was loaded to $8 \mathrm{MN}$ extensive acoustic emission was observed. But, gross fracture did not occur until it was unloaded; then, at a load of $7 \mathrm{MN}$, the skirts completely spalled off and longitudinal cracks running the length of the insulator were formed, as shown in Fig. 10 (resulting in an abrupt load decrease from $7 \mathrm{MN}$ to $6 \mathrm{MN}$ ). The formation of these massive cracks was preceded by a rapid increase in acoustic emission, for a period of about 5 seconds before the observable event.

b) Second Insulator

The second post insulator was subjected to a single load cycle, up to $3 \mathrm{MN}$, in an attempt to establish an effective proof test. The axial strains from the four strain gauges were within 13 percent of the average strain at $3 \mathrm{MN}$. This insulator was loaded at a rate of $0.18 \mathrm{MN} / \mathrm{min}$ to $3 \mathrm{MN}$; the initial unloading (to $2 \mathrm{MN}$ ) was conducted rapidly, at an average rate of $3 \cdot \mathrm{MN} / \mathrm{min}$, and then continued at a substantially reduced rate $(0.18 \mathrm{MN} / \mathrm{min})$ to zero load.

The acoustic emission from the second post insulator is also shown in Fig. 10. Again the acoustic emission rate increased as the load increased, and decreased during unloading; but the decrease was marginal in the rapid unloading regime (from 3 to $2 \mathrm{MN}$ ), which contrasts with the continuous decrease observed during slow unloading in the first post insulator. An untrasonic inspection of the post insulator after testing gave no indication of macrocrack formation.

\footnotetext{
An acoustic emission peak was noted at $4 \mathrm{MN}$. However, this cracking did not represent the general behavior of this insulator configuration because visual inspection showed that the cracking initiated from a portion of one of the skirts that had been damaged before testing.
} 
The proof tests described in the preceding section have generated important information about two aspects of the insulator proof test procedure; (a) the use of acoustic emission to monitor crack propagation, and (b) the lifetime assurances that can be provided by proof testing. These features of the proof test are discussed for both insulator configurations.

\section{I Acoustic Emission}

Acoustic emission during proof testing can result from:

(a) plastic deformation in the steel end caps, (b) frictional effects between the porcelain and cement, or (c) microcrack formation and macrocrack growth in the porcelain (or cement). It is clearly very important that an appreciation of the emission expected from each of these sources be developed before attempting to analyze the acoustic emission data.

\subsubsection{Plastic Deformation}

Plastic deformation results in intense acoustic emission if the dislocations move in discrete glide "packets". [6] This occurs only during the initial loading period when new dislocation sources are being generated, and the acoustic emission due to a deforming part will typically exhibit the features shown in Fig. 1l. Deformation of the steel end caps might, therefore, contribute to the emission during initial loading, but is unlikely to be a significant contribution during the constant load and unloading portions of a proof test cycle.

\subsubsection{Frictional Effects}

During proof testing slippage may occur at the porcelain/ metal/cement interfaces. Slippage will be particularly severe for cone insulators because the bearing surfaces are not orthogonal to the applied load. Similar slippage behavior might be expected during loading and unloading, although the amplitude will be somewhat reduced during unloading if the slippage is partially irreversible. Thus, some of the acoustic emission observed in proof tests of cone insulators can almost certainly be attributed to frictional effects during slippage. By contrast, we shall see later (Section 4.1.4) that frictional effects are unlikely to be the major source of acoustic emission in tests conducted on the post insulators 


\subsubsection{Macrocrack Growth}

Acoustic emission during macrocrack growth in porcelain has been investigated by Evans and Linzer. [2] They showed that the acoustic emission rate is approximately proportional to the crack velocity, (Fig. 12). A direct comparison between their acoustic emission data and the data in this paper is not possible, due to differences in specimen shape and size, the transducer location etc.; but their data illustrate the important trends needed for the qualitative analysis of macrocrack growth. A quantitative treatment can be performed and some objective conclusion reached with a modest amount of additional information (see Appendix) .

Cracks that initiate in the tensile zones ${ }^{*}$ of the cone insulator (type A zones) arrest in the structure, because they invariably propagate into adjacent compressive ${ }^{*}$ zones (type B zones). The tensile stresses that aid crack growth are greatest at the top and bottom bearing interfaces, decrease with distance from the interface, and finally become compressive approximately $0.15 \mathrm{~m}$ away. The crack growth rate is thus expected to exhibit an initial increase in zone $A$, reach a maximum value (see Appendix), and then decrease in zone B essentially to zero. As the crack velocity increases from zero to a maximum, the acoustic emission rate must also go through a maximum. Hence, a peak in the acoustic emission rate is expected when macrocrack growth occurs.

Peaks of this sort were observed in the cone insulators (Figs. 4 and 8) and correlated with macrocrack formation. No significant peaks were observed during the simulation proof test in the post insulators.

\footnotetext{
* The terms tensile zone and compressive zone are used here to describe the regions in the insulator prior to macrocrack development in which the largest normal stresses orthogonal to the observed crack propagation planes are, respectively, tensile and compressive; hereafter, these regions are referred to as zones $A$ and $B$, respectively.
} 
An estimate of the proportionality constant relating the acoustic emission rate and crack velocity can be determined for the cone insulators from the maximum acoustic emission rate and the time taken for macrocrack growth. The maximum acoustic emission rate during the peaks was approximately $10^{5}$ counts/s; the duration of the peaks was approximately $50 \mathrm{~s}$ and the crack growth was approximately $0.2 \mathrm{~m}$, giving an average crack velocity of $4 \times 10^{-3} \mathrm{~m} / \mathrm{s}$. If we assume that the average velocity is not very different from the maximum velocity, the proportionality is $2 \times 10^{7}$ counts/m (see the Appendix for a more detailed illustrative analysis); whereas the data of Evans and Linzer obtained on small specimens gave $10^{5}$ counts $/ \mathrm{m}$.

\subsubsection{Microcrack Formation}

It has been shown [2] that microfracture of quartz particles in porcelain is a profuse source of acoustic emission; and that the rate of acoustic emission depends on the rate at which the quartz particles break. The dependence of acoustic emission rate on stress and time has been quantified for several loading conditions. [2] These results are expanded in a companion paper [7] to give the acoustic emission rate, $d N / d t$, for a constant stress rate, $\dot{\sigma}_{L}$, constant stress, $\sigma_{p}$, and constant unloading rate, $\dot{\sigma}_{u}$. For a constant stress rate, $\dot{\sigma}_{L}$, the acoustic emission rate (dN/dt) due to particle fracture for a homogeneous stress $\sigma$, except for stresses close to zero, is: [7]

$$
\log (d N / d t)=\left\{[m(n+1) /(n-2]-1\} \log \sigma+\{1-[m /(n-2)]\} \log \dot{\sigma}_{L}+\phi\right.
$$

where $\mathrm{m}$ is the shape parameter for the quartz particle fracture stress distribution, $\phi$ is a constant, and $\mathrm{n}$ is the slow crack growth exponent (see Appendix). For a constant stress, $\sigma_{a^{\prime}}$ (following loading) the acoustic emission rate, except for very short times is: [7] 


$$
\log (a N / d t)=\{[m /(n-2)]-1\} \log t+\log (d N / d t)_{L}+\phi^{\prime}
$$

where $\phi^{\prime}$ is a constant and $(d N / d t)_{L}$ is the acoustic emission rate immediately after loading is completed. For unloading, at a constant rate, the acoustic emission rate except for stresses close to $\sigma_{a}$ is:

$$
\begin{aligned}
\log (d N / d t)=n \log \left(\sigma / \sigma_{p}\right)-\{(n-m-2) /(n-2)] & \log \left\{1+\phi^{n}\left[1-\left(\sigma / \sigma_{p}\right)^{n+1}\right]\right\} \\
& +\log \left(d^{n} / d t\right)
\end{aligned}
$$

where $\phi^{\prime \prime}$ is a constant that depends on the loading, holding and unloading times; and (dN/dt) $)_{p}$ is the acoustic emission rate at the proof stress immediately prior to unloading. These three relations can be used in combination to predict the acoustic emission expected during a proof test cycle, (Fig. 13), when the acoustic emission is due onlv to microcrack formation. Alternatively, this source of acoustic emission can be used as an approximate monitor of stress variations that may occur in a component, due to unidentified or extraneous effects. Some similarity between the predicted and observed emission rates (Figs. 13 and 9) is apparent for the post insulators, suggesting that acoustic emission in the post insulators is due mainly to microcrack formation (occurring in the porcelain and/or the cement). A more quantitative comparison can be made by using the acoustic emission test data to calculate $m$ and $n$ of Eqs. (1) through (3). The slopes of predicted curves in Fig. 13 are given by, $x=[m(n+1) /(n-2)]-1$, for the constant loading rate portion of the curve and $y=[m /(n-2)]-1$ for the constant stress portion. By substituting for $\mathrm{x}$ and $\mathrm{y}$ (the measured values of these slopes, , we find: $m \simeq 5$ and $n \simeq 10$. Similar values were obtained in the laboratory on flexural specimens cut from an equivalent insulator [2] $(m=3$ to $4 ; n=10$ to 12$)$, thus adding additional credence to our suggestion that microcracking (occurring mostly in the porcelain) is the primary source of acoustic emission in these insulators.

The values of $\mathrm{m}$ and $\mathrm{n}$ can now be used to compute the acoustic emission rate, due to microcracking, for a reversible, elastic system 
during unloading. [7] The results for the post insulator, shown in Fig. 14, indicate an acoustic emission rate exceeding that expected for a reversible system. A similar calculation for the cone insulators would indicate a much larger discrepancy. This additional acoustic emission is almost certainly due to residual stress development (resulting from some irreversible slip at the porcelain/cement interface), which causes additional microcracking; and, for the cone insulators, leads to macrocrack formation. A mmeasure of the severity of the residual stress can be computed by substituting the observed acoustic emission rate on unloading into $\mathrm{Eq}$. (3). [7] The result (Fig. 15) indicates a small, but significant, residual stress that persists to zero load.

\subsection{Lifetime Assurance After Proof Testing}

\subsubsection{Cone Insulator}

The observations of macrocracking and profuse acoustic emission during unloading of the cone insulators show that extensive irreverisble slippage occurs in this configuration at the porcelain/cement interfaces, which leads to substantial residual stress development during load release. The stresses that develop during unloading apparently exceed the stresses at the proof load. Hence, no realistic lifetime assurances after proof testing can be provided.

In systems that exhibit substantial irreversibility during proof testing the only merit of proof testing is the assurance that there will be no instantaneous failure during installation. This can be ensured by proof loading to a load just in excess of the service load (by say 5 percent). This load should then be maintained on the component until installation, using a clamping fixture, to avoid macrocracking in the period between proof testing and installation.

Finally, it is noted that although this proof test procedure gives no guarantee that all surviving insulators will resist in-service macrocracking, a proportion of the insulators will give a satisfactory in-service performance. The proportion that gives good performance 
depends on the statistical nature of the flaw size distribution in the critical parts of the insulators, [1.4] i.e., near the top and bottom interfaces. The distribution function is difficult to obtain and is notoriously dependent on fabrication variables, [8] but approximate values could be obtained from a survey of the performance of insulators already in service.

\subsubsection{Post Insulator}

Residual stress development also occurs in the post insulators during unloading, but the stresses are comparatively modest, and not large enough to generate macrocracks. This configuration thus exhibits the basic features needed for effective lifetime assurances after proof testing.

Quantitative lifetime predictions after proof testing require values for the maximum stress during the proof test, $\sigma_{p}$, and the maximum stress during service, $\sigma_{a}$. [1] The ratio $\sigma_{p} / \sigma_{a}$ then gives the minimum failure time from Fig. 3, if the stress distributions are comparable. [1,4] For a system that exhibits reversible behavior, this ratio is given directly by the ratio of the proof load to the service load. But, for a system that exhibits some irreversibility, this load ratio does not suffice. Instead, a detailed stress analysis (for the complete proof cycle and the service condition) is needed to obtain values for the maximum stress in the proof test, and its distribution, and the maximum in-service stress. This analysis has not been performed, and hence, we cannot yet determine whether an effective proof test procedure for this system is a practical feasibility. We suggest that urgent attention is devoted to this stress analysis (both analytically using stress calculations and empirically using acoustic emission) to enable this issue to be resolved.

\section{CONCLUSIONS AND RECOMMENDATIONS}

Proof test have been conducted on cone and post porcelain insulators. At the proof loads needed to guarantee approximately $40 \mathrm{hrs}$. lifetime 
without macrocracking, extensive irreversible interface slippage occurs in the cone configuration, and this leads to macrocracking while unloading. This specific configuration is thus not capable of effective overload proof testing. It is recommended, therefore, that the insulators are only proof tested to a load just above the in-service load, if an assurance of no immediate "failures" during installation is required (and that nondestructive inspection is used to identify the proof test failures). No significant lifetime predictions can be provided for this insulator.

The post insulator can be subjected to the loads needed for effective overload proof testing without excessive slippage and without gross macrocracking. This configuration thus has the basic prerequisites for lifetime prediction after proof testing. However, the detailed prediction requires information about the stress distribution in these insulators, both during proof testing and in service. It is hoped that this information can be provided by stress analysis and acoustic emission measurements. Then it will be possible for proof test procedures to be developed.

Acoustic emission was monitored throughout the proof tests and was found to generate information about the two most crucial problems in insulator proof testing: internal stress development and macrocracking (the latter constituting a proof test failure in compression proof testing). Analyses have been presented which form the basis for the quantitative determination of residual stress development and for the detection of macrocracking events using acoustic emission. Acoustic emission measurements during proof testing thus permit a substantial extension of the proof testing technique to quantitative lifetime predictions, although more extensive calculations of acoustic emission rate are required to explore the full potential of the technique in this application. Finally, for future proof test studies, we recommend that a large acoustic emission system, employing several correlated transducers, is utilized. This would add an extra dimension to the study, by permitting spatial resolution of the acoustic emission sources. 
APPENDIX

\section{ACOUSTIC EMISSION DUE TO MACROCRACKING}

Firstly, we need to obtain the relation between the stress intensity factor, $\mathrm{K}_{I}$, and the crack length for the component. This is determined for a symmetrically loaded central through crack from the relation: [9]

$$
K_{I}=2\left(\frac{a}{\pi}\right)^{1 / 2} \int_{0}^{a} \frac{\sigma_{y}}{\left(a^{2}-x^{2}\right)^{1 / 2}} d x
$$

where $\sigma_{y}$ is the stress orthogonal to the crack plane and $2 \mathrm{a}$ is the crack length; this relation also applies, to a good approximation, for an edge crack of length a.

For illustration purposes we shall now consider an edge crack propagating in a linearly decreasing stress field (Figl.16a):

$$
\sigma_{y}=\sigma_{t}\left[1-\frac{x}{a^{*}}\right]
$$

where $\sigma_{t}$ is the maximum tension in zone $A$ and $a^{*}$ is the size of zone $A$. Substituting $\sigma_{y}$ in Eq. (Al) and integrating gives:

$$
K_{I}=\sigma_{t} \sqrt{\pi a}\left[1-\frac{2 a}{\pi a^{\star}}\right]
$$

or, if we define $K_{0}$ as the stress intensity factor for initial flaw propagation ( $K_{0}=\sigma_{t} \sqrt{\pi a_{0}}$, where $a_{0}$ is the initial flaw size)

then:

$$
K_{I}=K_{0} \sqrt{\frac{a}{a_{0}}}\left(1-\frac{2 a}{\pi a^{*}}\right)
$$

Next, we shall differentiate to determine the maximum stress intensity factor, $\left(\mathrm{K}_{\mathrm{I}}\right)_{\max }$; this gives 


$$
d K=\frac{K}{\sqrt{a_{0}}}\left[\frac{1}{2 \sqrt{a}}-\frac{3 \sqrt{a}}{\pi a^{*}}\right]=0
$$

so that $a=\pi a^{*} / 6$ and:

$$
\left(K_{I}\right)_{\max }=\frac{2 K_{0}}{3} \sqrt{\frac{\pi a^{*}}{6 a_{0}}}
$$

Also, note that $\mathrm{K}_{I}=0$, when $a=\pi a^{*} / 2$. Hence, we can construct relatively simple ( $\left.K_{I}, a\right)$ diagrams for this system, as depicted in Fig. $16 \mathrm{~b}$.

Now, the $\left(K_{I}, a\right)$ relation can be combined with the $\left(K_{I}, V\right)$ relation to obtain velocity, time diagrams, as follows;

Using, $\mathrm{V}=\mathrm{AK}_{I}{ }^{\Omega}$, for the slow crack growth relation [1] (where $\mathrm{n}$ and $\mathrm{A}$ are separate quantities for each region of crack growth), and combining with Eq. (A4) gives;

$$
t=\frac{a_{0}^{n / 2}}{A K_{0}^{n}} \int_{a_{1}}^{a_{2}} \frac{\left[1-2 a / \pi a^{*}\right]}{a^{n / 2}} d a
$$

where $t$ is the crack propagation time. Expansion and integration then gives, for $a_{2}>a_{1}$;

$$
t=\frac{2}{A K_{0}^{n}} \frac{a_{0}^{n / 2}}{a_{1}^{n-2 / 2}}\left[\frac{1}{n-2}+\frac{n}{(n-4)}\left(\frac{2 a_{1}}{\pi a^{*}}\right)+\frac{n(n+1)}{2(n-6)}\left(\frac{2 a_{1}}{\pi a^{*}}\right)^{2}+\cdots \cdot\right]
$$

For $2 a_{1} / \pi a^{* n}<n$, this becomes

$$
t=\frac{2 a_{I}}{A K_{I i}^{n}(n-2)} \equiv \frac{2 a_{I}}{V_{I}(n-2)} \approx \frac{2\left(K_{I i}\right)^{2}}{\pi \sigma_{t}^{2} V_{I}(n-2)}
$$

where $V_{1}$ is the crack velocity when $a=a_{1}$. The total duration of the macrocracking event is obtained by putting $a_{1}=a_{0}$ and $v_{1}=V_{0} \cdot$ But, a more important quantity for the acoustic emission analysis is the duration which gives an acoustic emission rate in excess of the background. This is obtained by putting $V_{1}$ equal to the velocity, $V^{\prime}$, where the acoustic emission due to macrocracking exceeds the background emission; and $a_{1}$ becomes the corresponding crack length. 


\section{References}

I. A. G. Evans and S. M. Wiedernorn, NBSIR 73-147 (March 1973), IntI. Jnl. Frac., in press.

2. A. G. Evans and M. Linzer, Jnl. Amer. Ceram. Soc. 56, 575 (1973).

3. A. G. Evans and E. R. Fuller, Mater. Sci. Eng., to be published.

4. S. M. Wiederhorn, Ceramics for High Performance Applications, in press.

5. A. H. Heuer, private communication.

6. A. S. Tetelman and A. G. Evans, Fracture Mechanics of Ceramics, 2, 895, (1974).

7. A. G. Evans, J.Am. Ceram. Soc., to be published.

8. A. G. Evans and T. G. Langdon, Progress in Materials Science, to be published.

9. S. Vaidyanathan and I. Finnie, Jnl. of Basic Engineering (ASME), June 1971, p. 242 . 


\section{Figure Captions}

Fig. 1. A typical cone insulator used in this study.

Fig. 2. A typical post insulator used in this study.

Fig. 3. A proof test diagram for porcelain in humid environments ${ }^{2}$, giving the minimum service life time as a function of the service stress, $\sigma_{\mathrm{a}}$, at various proof stress levels, $\sigma_{\mathrm{P}}$.

Fig. 4. The relation between acoustic emission rate and load obtained on a cone insulator loaded to $11 \mathrm{MN}$, and unloaded rapidly. The large rate increase during unloading (just prior to zero load) can be attributed to macrocrack formation.

Fig. 5. An example of a laminar crack formed in a cone insulator.

Fig. 6. A schematic of the laminar and orthogonal cracks that form in cone insulators.

Fig. 7. An example of a longitudinal crack in a cone insulator.

Fig. 8. The acoustic emission rate obtained on a second cone insulator loaded to $11 \mathrm{MN}$ and unloaded slowly. An acoustic emission peak appears during unloading at $9 \mathrm{MN}$, and has been attributed to macrocracking.

Fig. 9. The acoustic emission rates obtained on the post insulators during loading to $3 \mathrm{MN}$ and unloading.

Fig. 10. A post insulator after testing to 7 MN and unloaded to $6 \mathrm{MN}$.

Fig. 11. The acoustic emission expected due to plastic deformation of the steel end caps.

Fig. 12. The relation between acoustic emission rate and crack growth rate during slow crack growth in porcelain. 2

Fig. 13. The predicted acoustic emission rate from microcracking in an elastic, reversible system.

Fig. 14. A comparison of the acoustic emission rates measured during unloading with the rates predicted for a reversible, elastic system.

Fig. 15. The relative residual stress in the post insulators during unloading as predicted from the excess acoustic emission; $\sigma_{p}$ is the residual stress and $\sigma_{D}$ is the stress at the proof load.

Fig. 16. (a) A schematic of a linearly decreasing stress field defining the parameters used in the text.

(b) The relation between stress intensity factor, $\mathrm{K}_{\mathrm{I}}$, and crack length, $a$, for the stress field in Fig. 16 (a). 


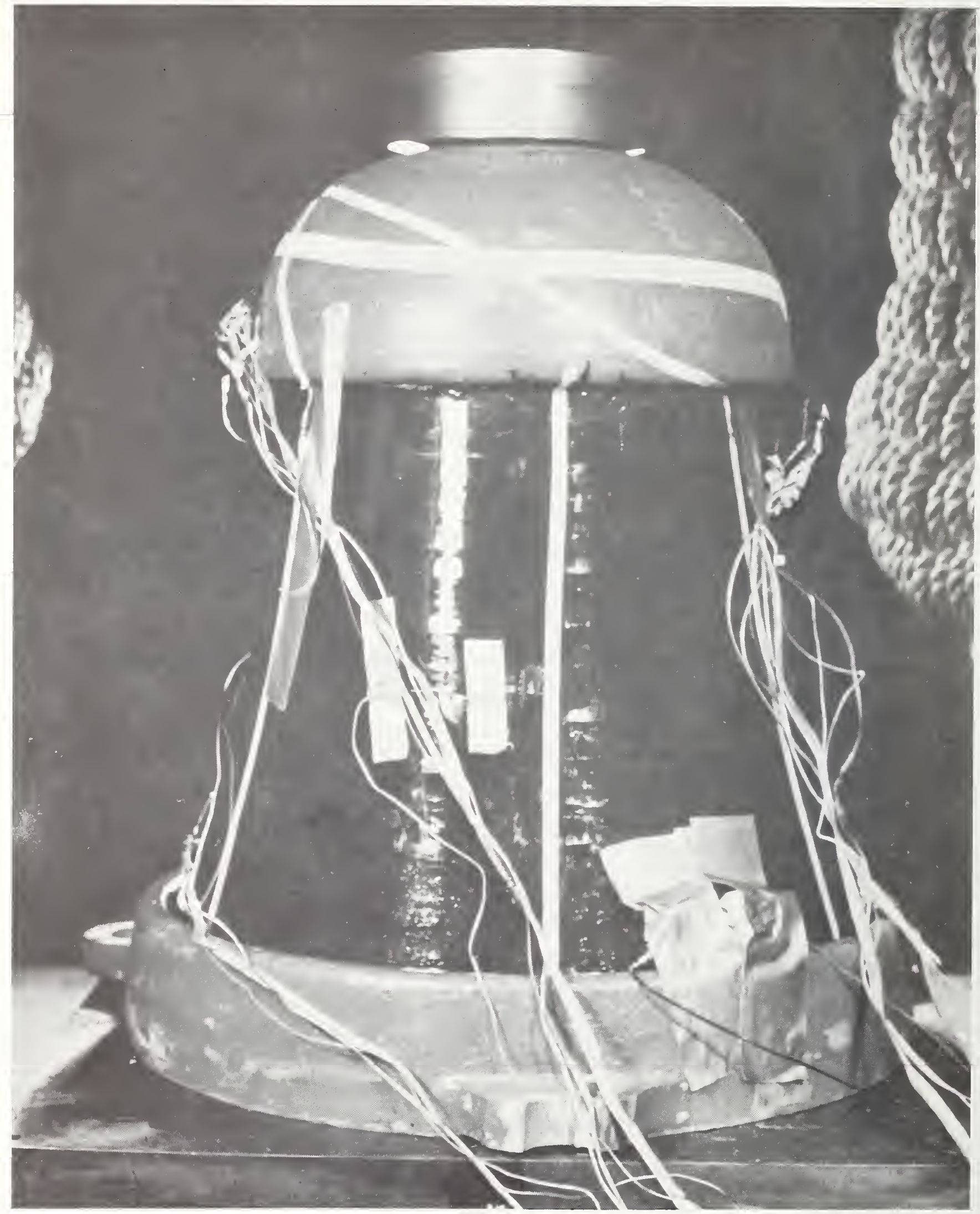

Fig. 1. A typical cone insulator used in this study. 


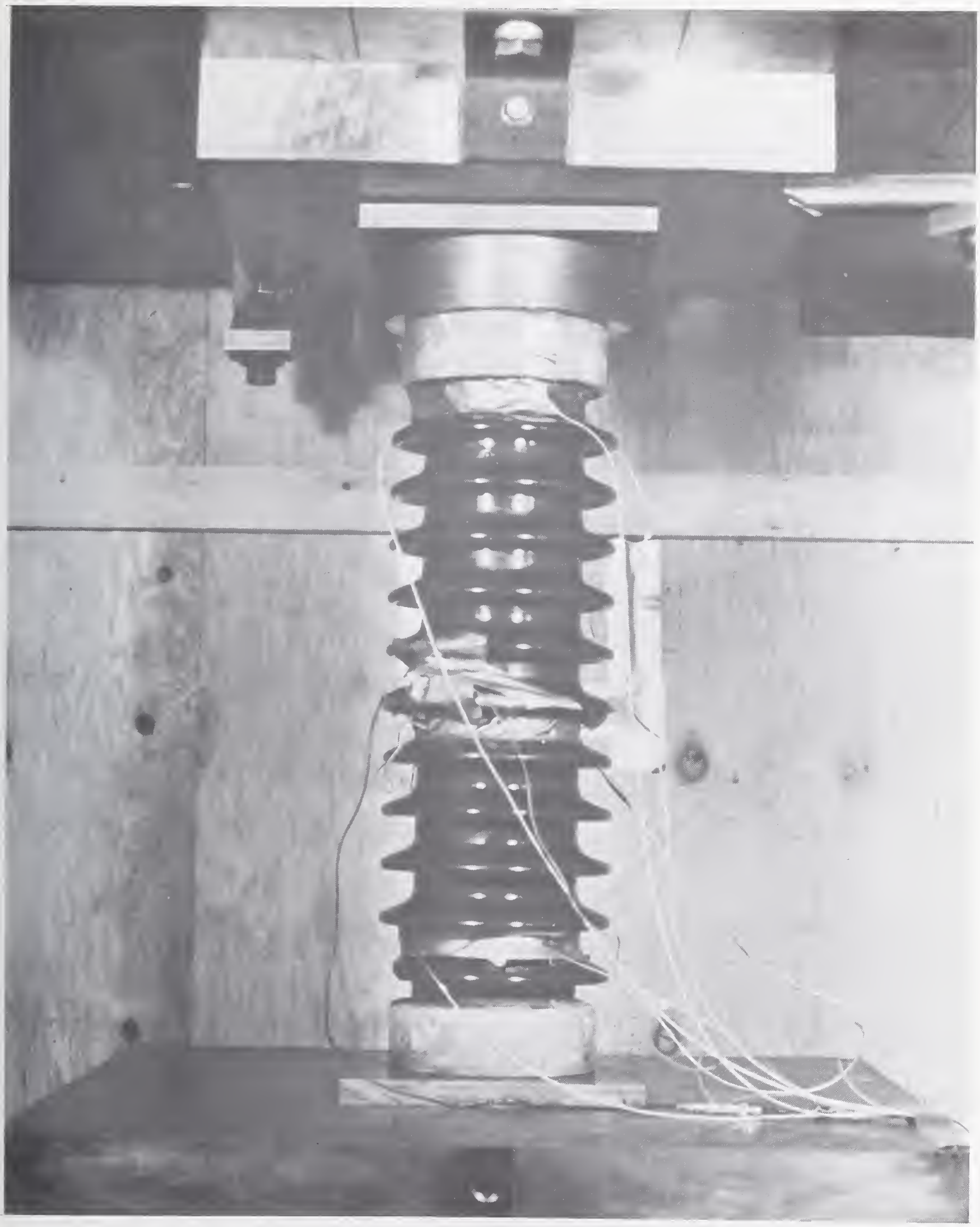

Fig. 2. A typical post insulator used in this study. 


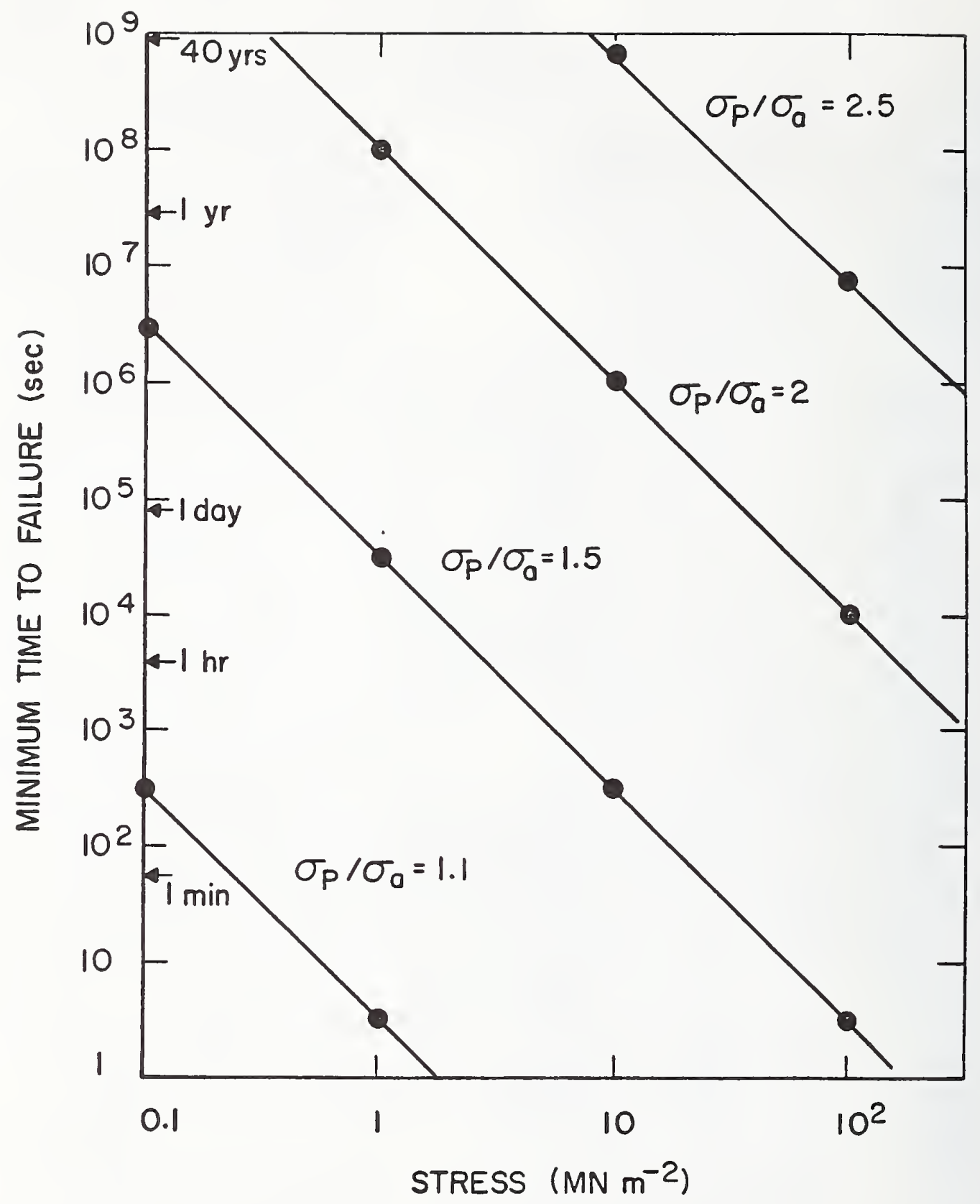

Fig. 3. A proof test diagram for porcelain in humid environments ${ }^{2}$, giving the minimum service life time as a function of the service stress, $\sigma_{a}$, at various proof stress levels, $\sigma_{P}$. 


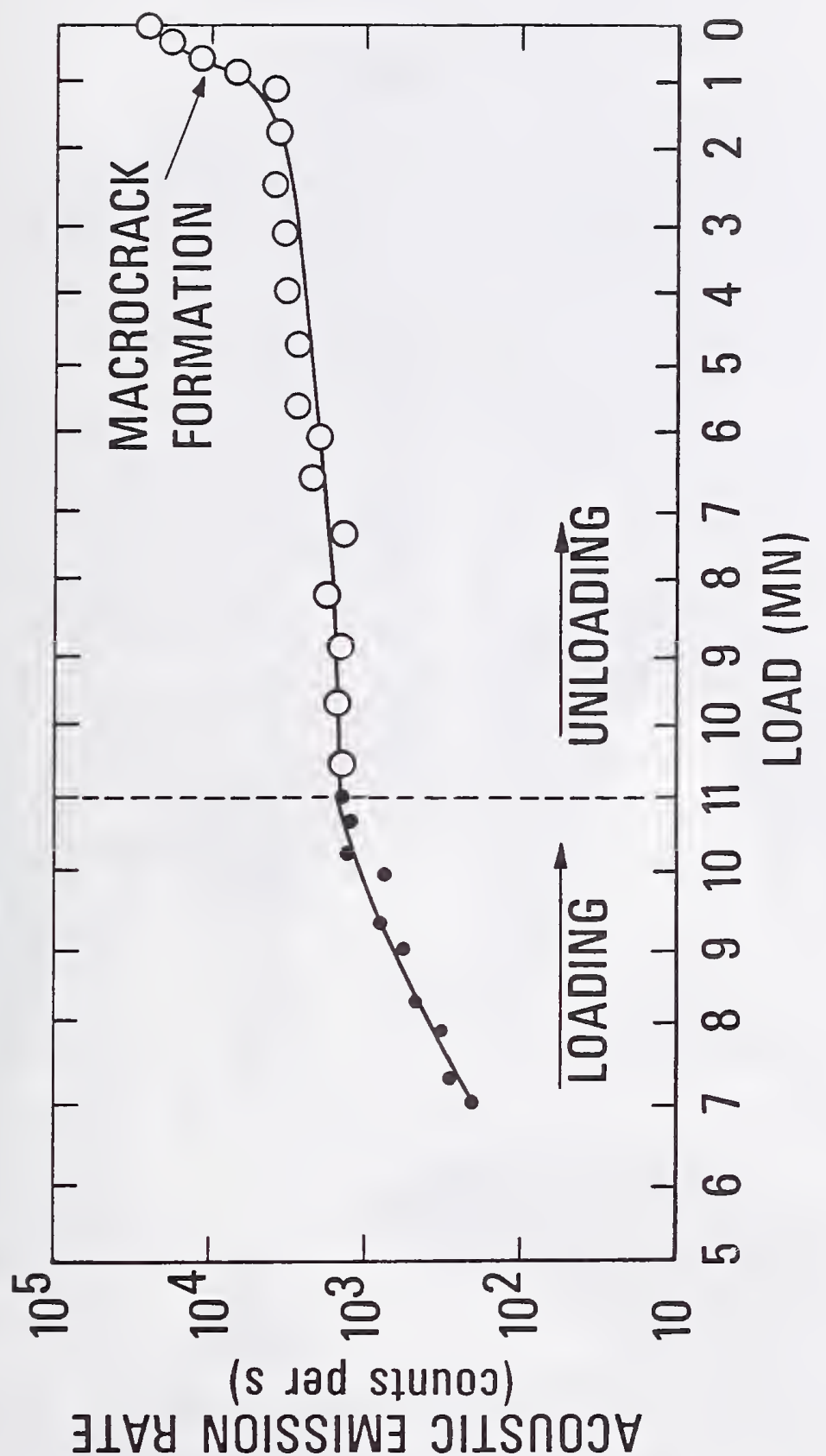

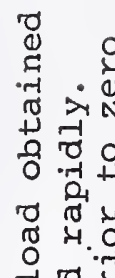

강

व

त० 0 of

(1) ⿷匚丁口

历

다 ⿷匚

दू $\pi \cdot \pi$

-

学学告

뎡

वृ न्न म्र

บ 0 界

तो $7 \cdot$ ह

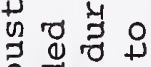

o r

त 0 थ 8

$\varepsilon^{-1} \stackrel{0}{0}$

का $\rightarrow$ \& 3

(1) 0 บ :

3.5

政

寻嵒 $\sigma$

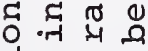

䒕号宁

Tी

(i) 0

(1) ซิ

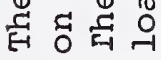

$\dot{\nabla}$

.

$\exists \perp \forall Y$ NOISSIW JIISกOJ 


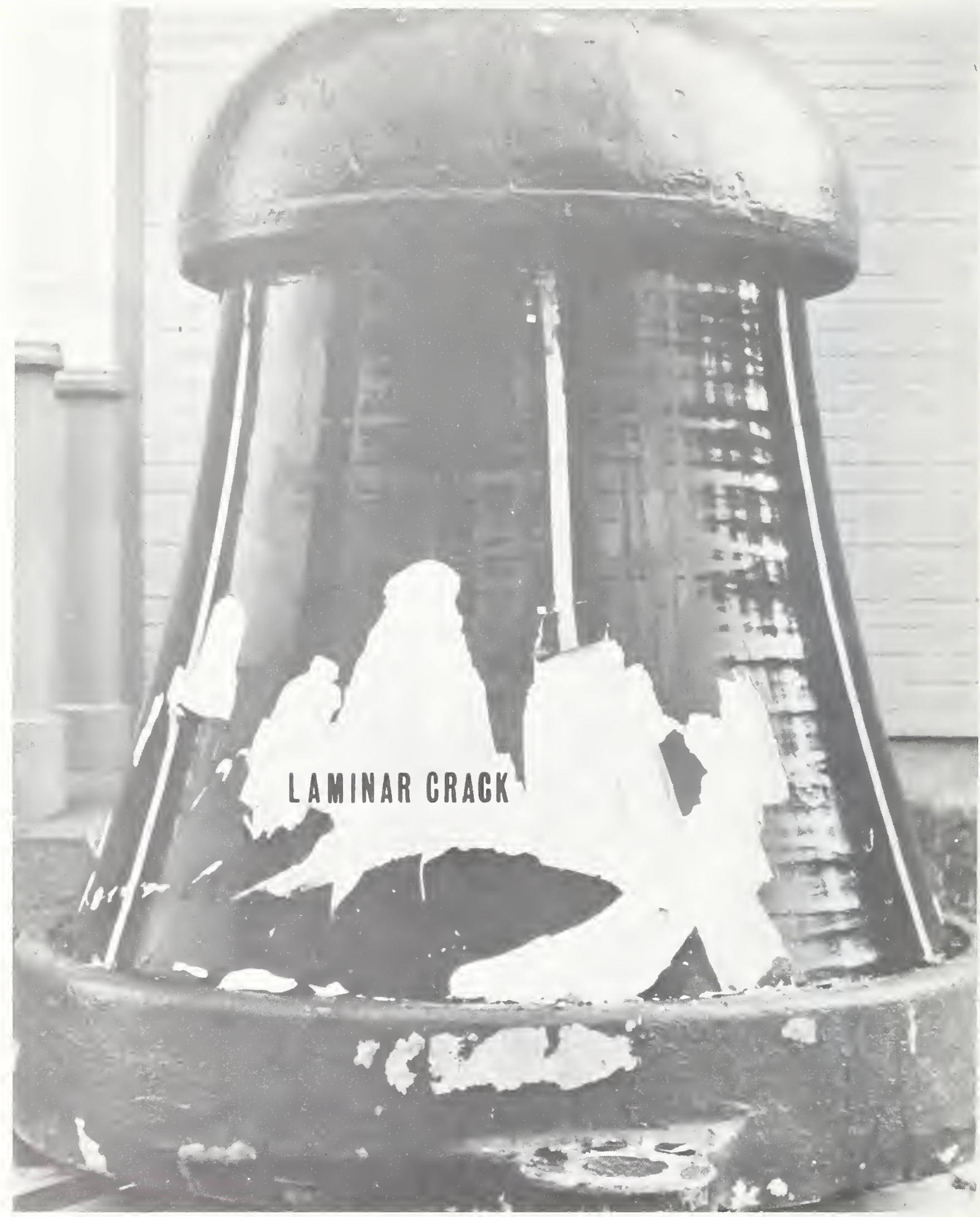

Fig. 5. An example of a laminar crack formed in a cone insulator. 


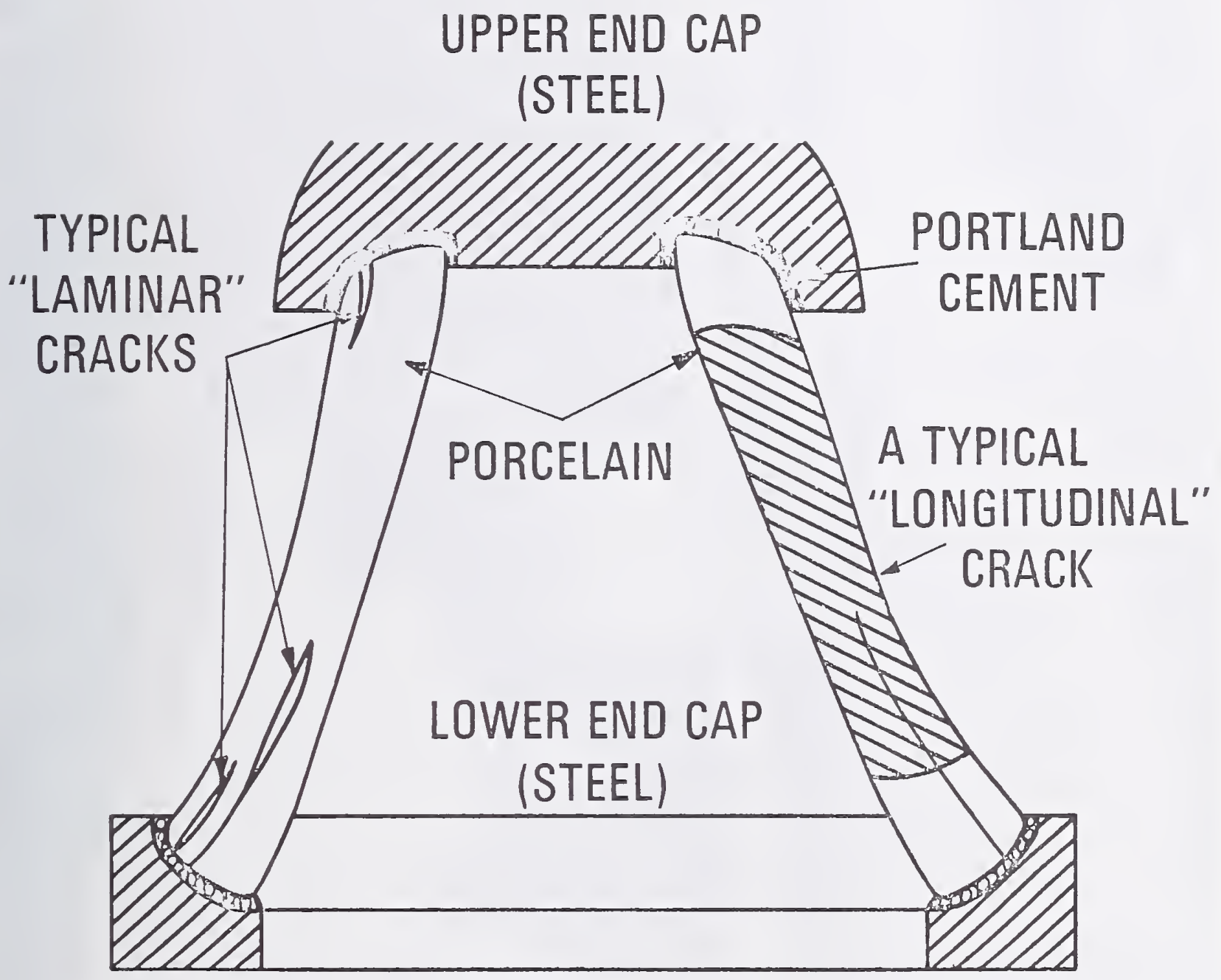

Fig. 6. A schematic of the laminar and orthogonal cracks that form in cone insulators. 


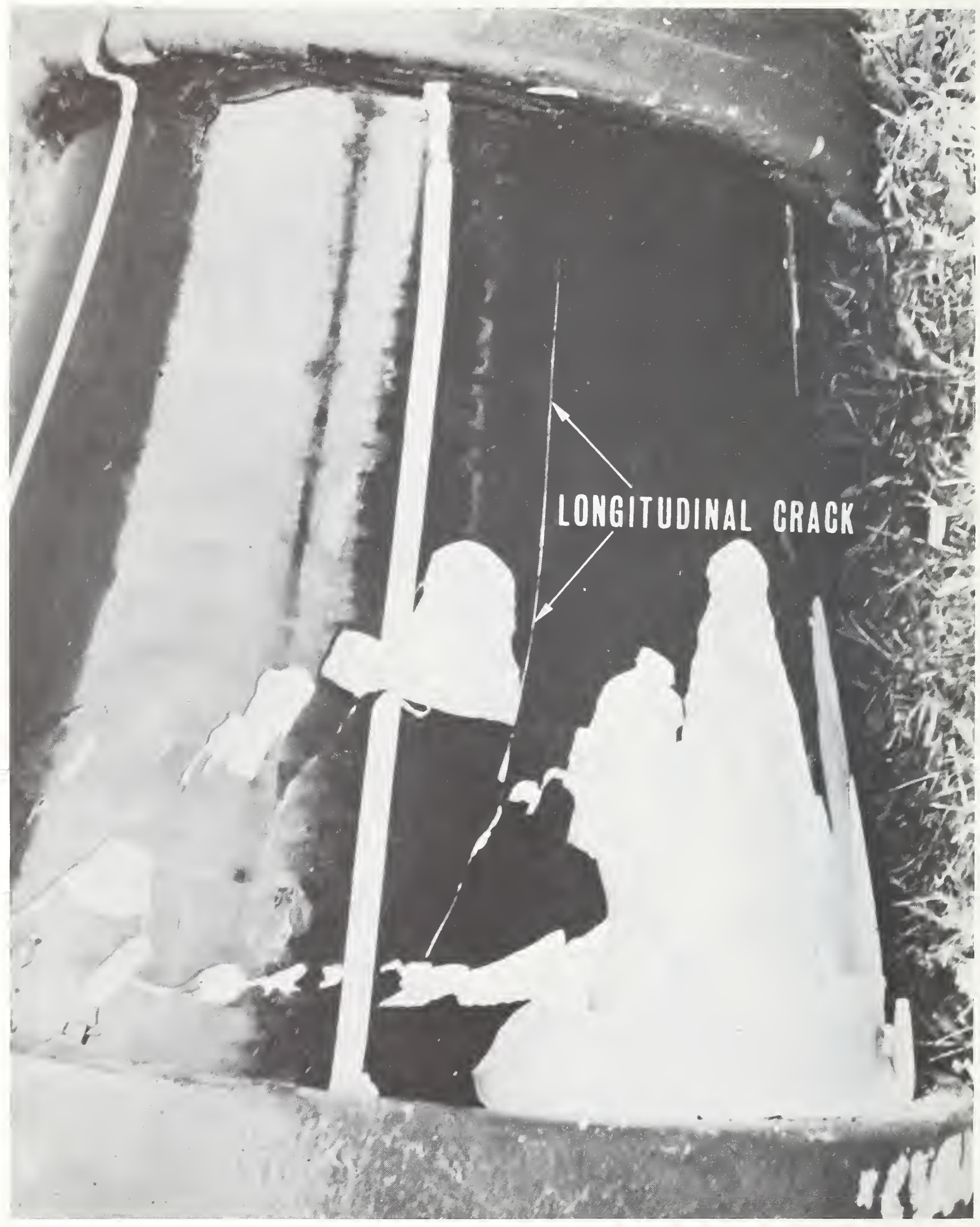

Fig. 7. An example of a longitudinal crack in a cone insulator. 

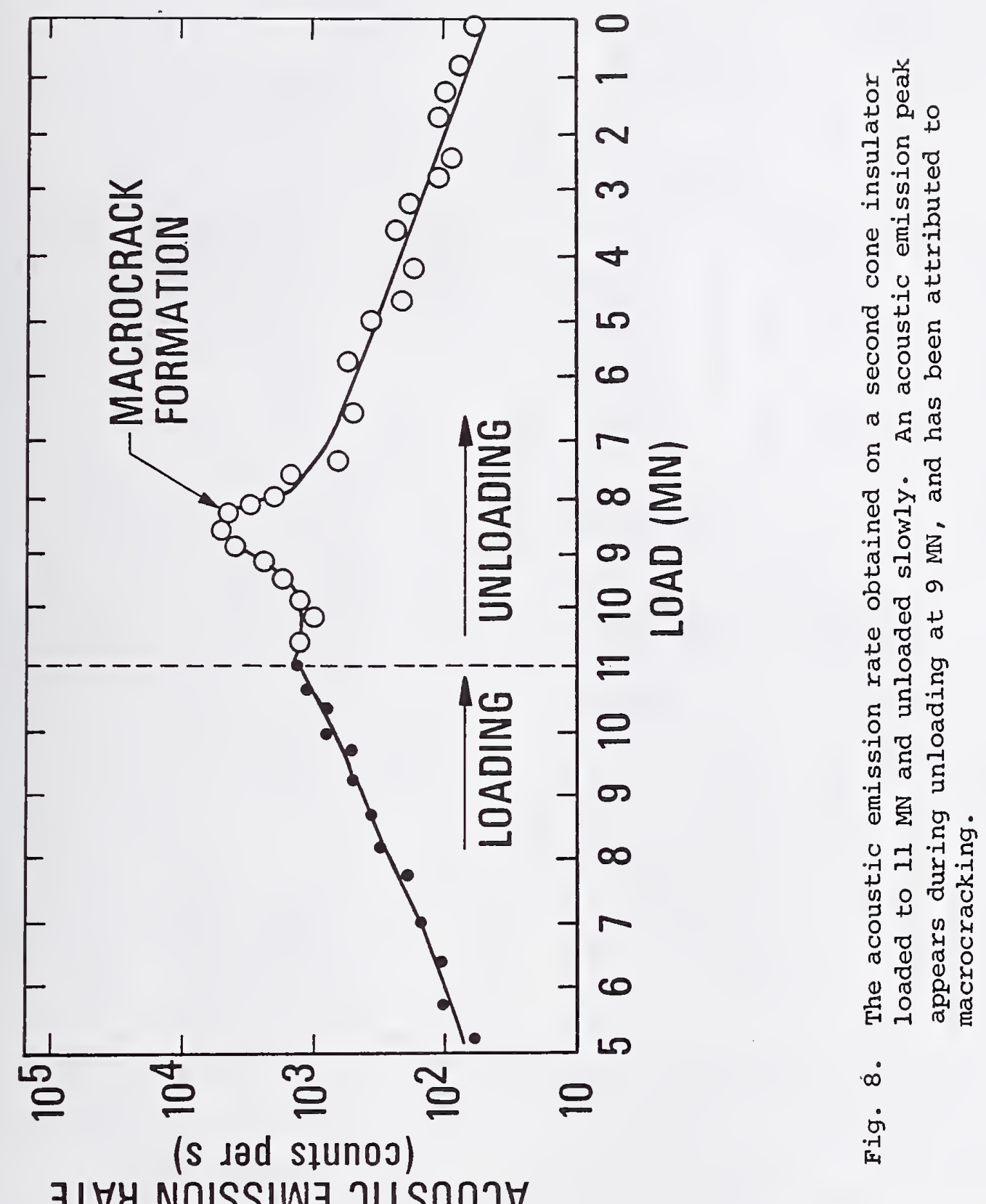

$\exists \perp \forall Y$ NOISSIW $\exists$ JILSกOJ 


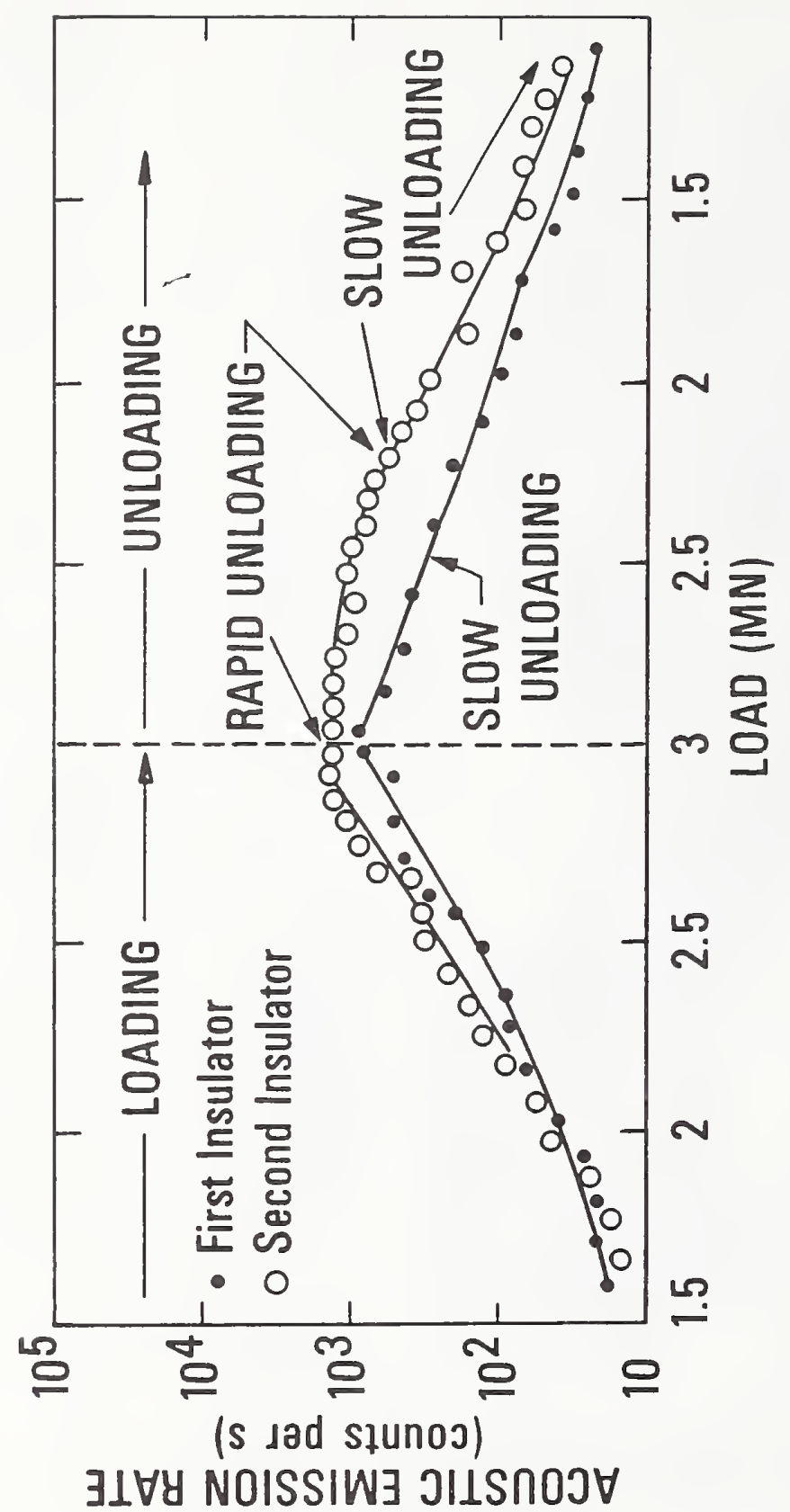

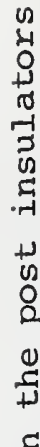

ธุ

ชु

.

疍

응 도

is 氙

i

实 $\exists \perp \forall$ Y NOISSIW JILSกOJ 


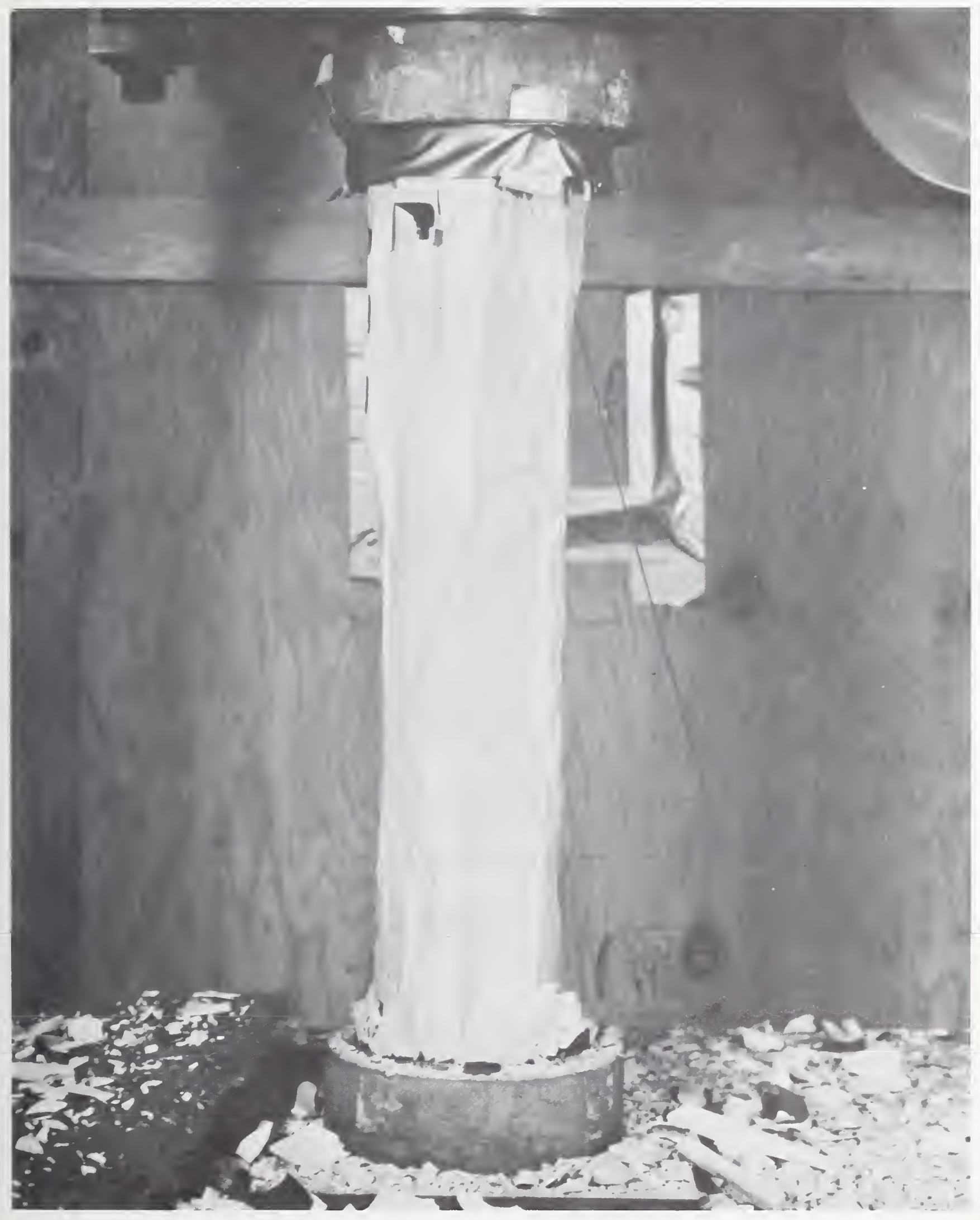

Fig. 10. A post insulator after testing to $7 \mathrm{MN}$ and unloaded to $6 \mathrm{MN}$. 


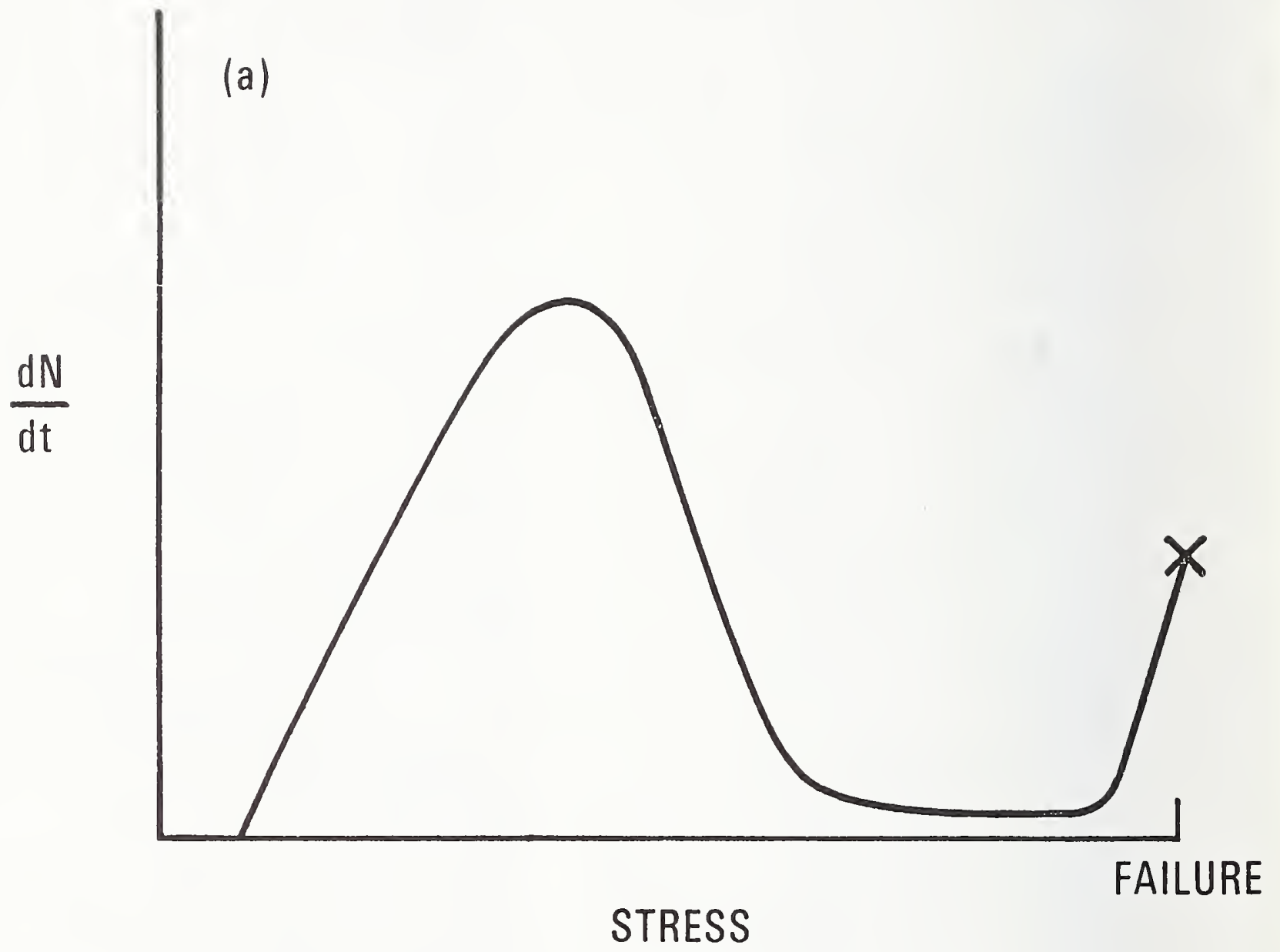

Fig. 11. The acoustic emission expected due to plastic deformation of the steel end caps. 


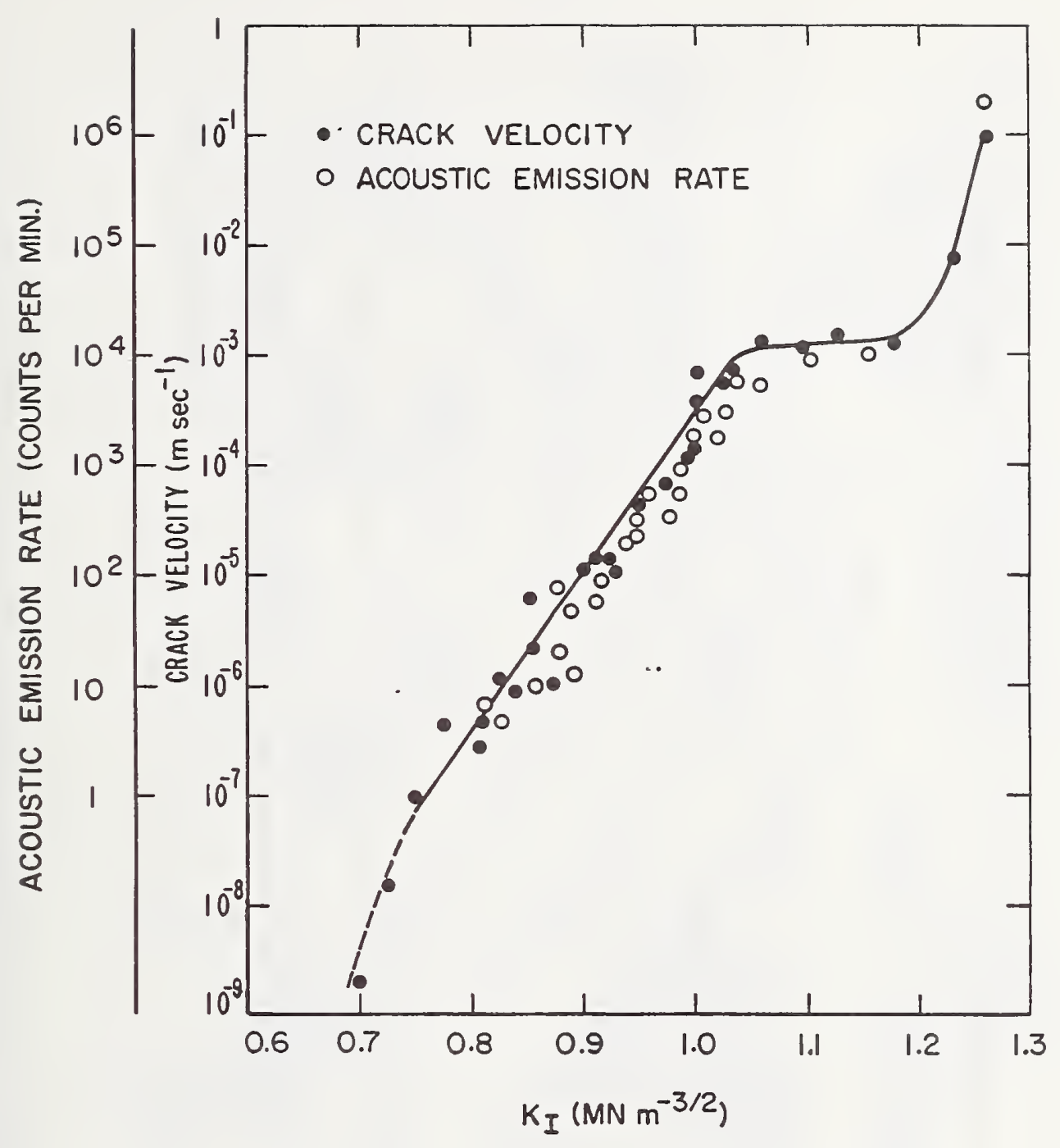

Fig. 12. The relation between acoustic emission rate and crack growth rate during slow crack growth in porcelain. 2 


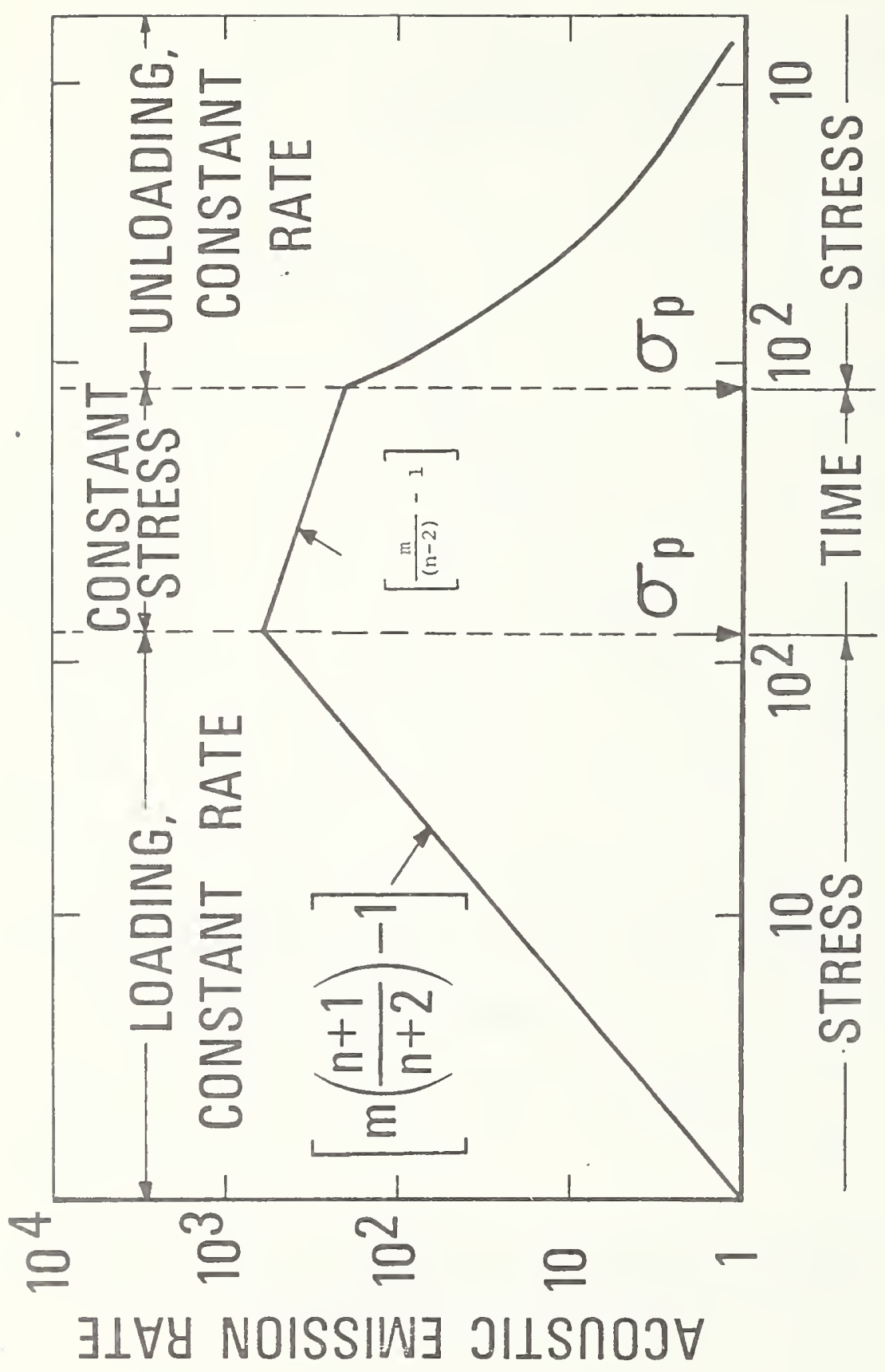

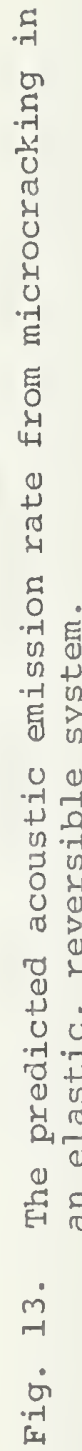




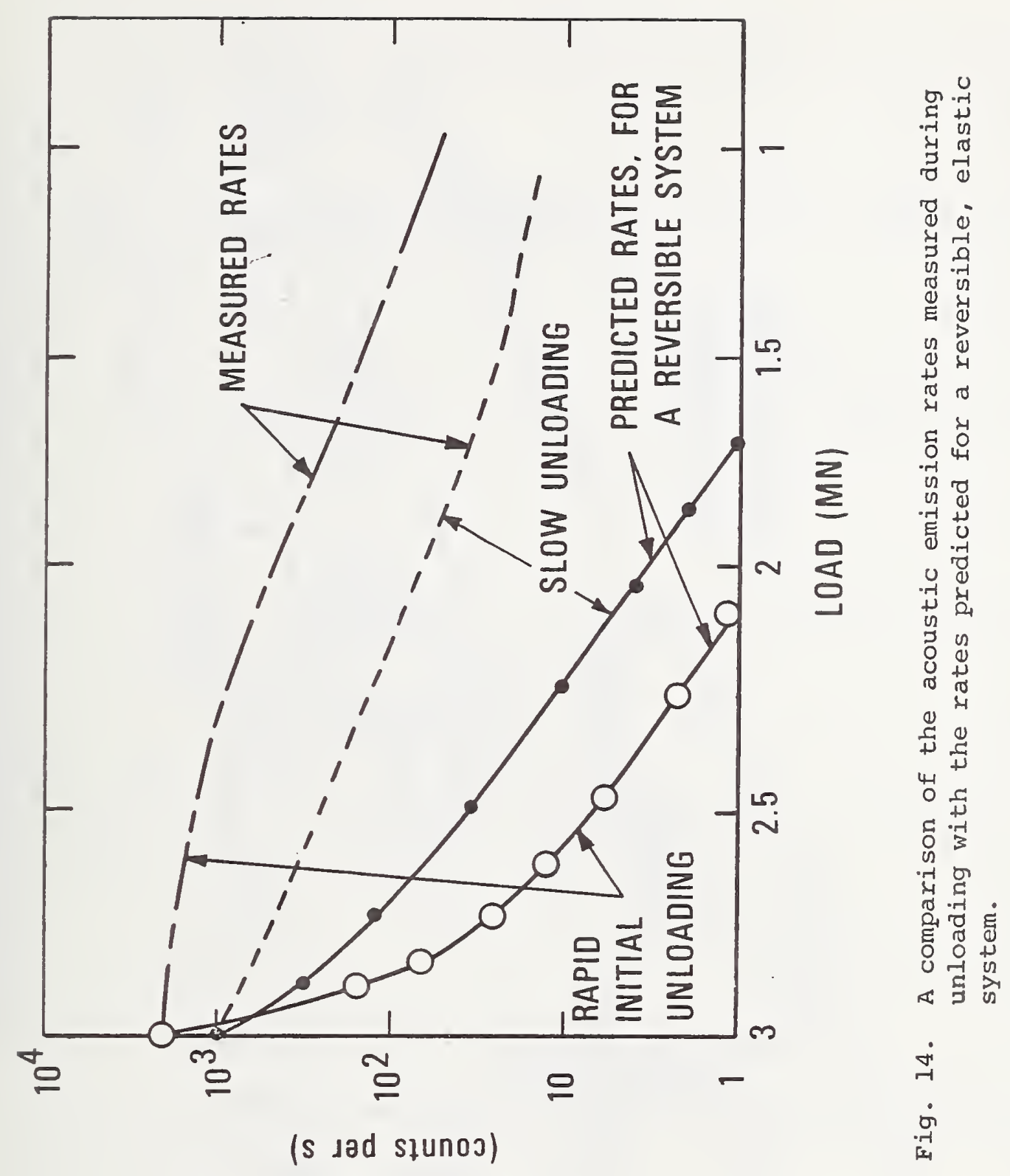

$\exists \perp \forall Y$ NOISSIW JILSกOJ 


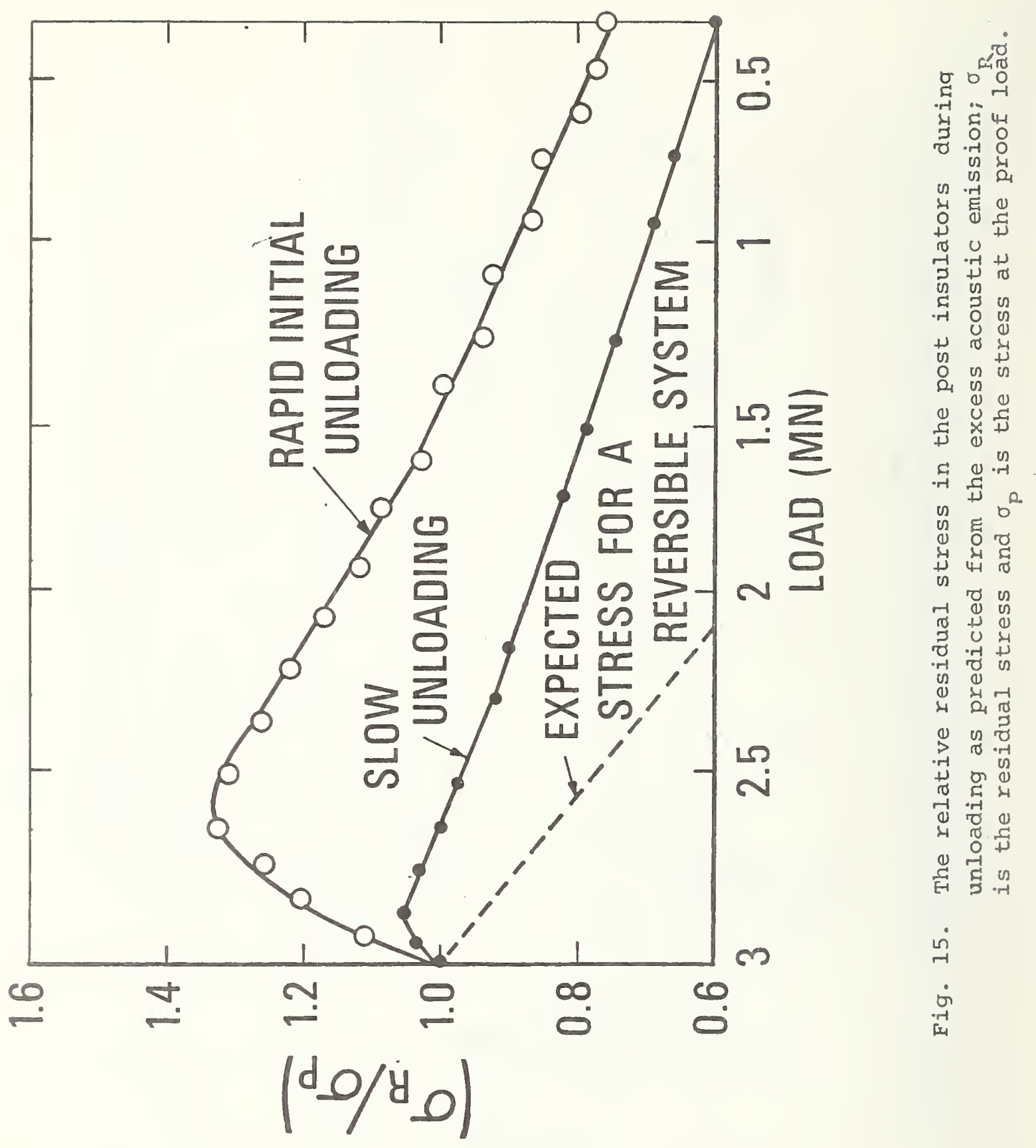



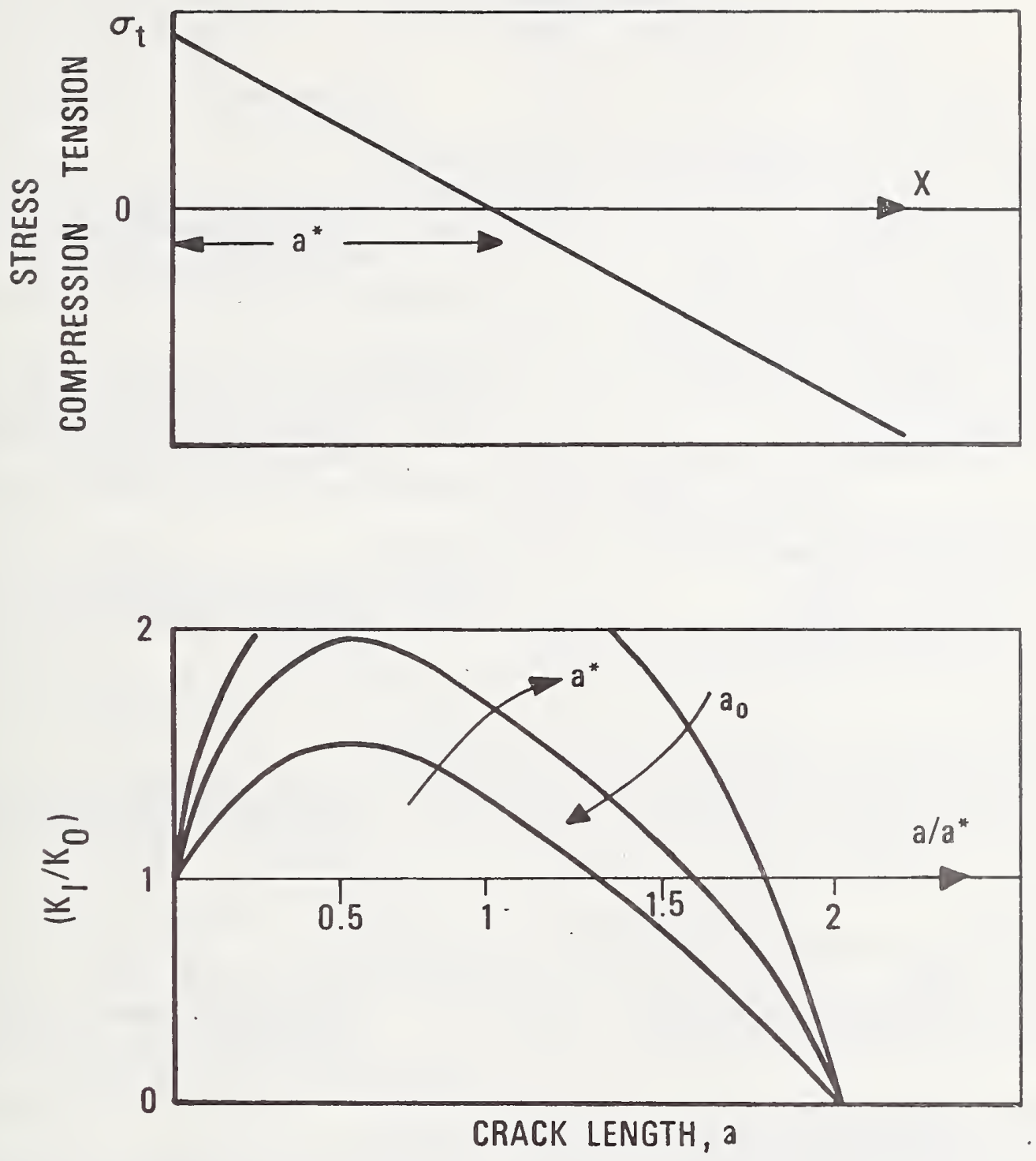

Fig. 16. (a) A schematic of a linearly decreasing stress field defining the parameters used in the text.

(b) The relation between stress intensity factor, $K_{I}$, and crack length, $a$, for the stress field in Fig. 16 (a). 
Organization

Office of Naval Research

Department of the Navy

Attn: Code 471

Arlington, Virginia 22217

Director

Office of Naval Research

Branch Office

495 summer street

Boston, Massachusetts 02210

Commanding officer

Office of Naval Research..

New York Area Office

207 West 24th Street

New York, New York 10011

Director

Office of Naval Research

Branch Office

219 South Dearborn Street

Chicago, Illinois 60604

Director

Office of Naval Research

Branch Office

1030 East Green Street

Pasadena, California 91101

Commanding Officer

Office of Naval Research

San Francisco Area Office

San Francisco, California 94102

Commanding officer

Naval Weapons Laboratory

Attn: Research Division

Dahlgren, Virginia 22448
Organization

Director

Naval Research Laboratory

Attn: Technical Information Officer Code 2000

Washington, D. C. 20390

Director

Naval Research Laboratory

Attn: Technical Information officer Code 2020

washington, D. C. 20390

Director

Naval Research Laboratory

Attn: Technical Information Officer Code 6000

Washington, D. C. 20390

Director

Naval Research Laboratory

Attn: Technical Information Officer Code 6100

Washington, D. C. 20390

Director

Naval Research Laboratory

Attn: Technical Information officer Code 6300

Washington, D. C. 20390

Director

Naval Research Laboratory

Attn: Technical Information Officer Code 6400

Washington, D. C. 20390

Director

Naval Research Laboratory

Attn: Library

Code 2029 (ONRL)

Washington, D. C. 20390 
Commander

Naval Air Systems Command

Department of the Navy

Attn: Code AIR 320A

Washington, D. C. 20360

Commander

Naval Air system Command

Department of the Navy

Attn: Code AIR 5203

Washington, D. C. 20360

Commander

Naval Ordnance Systems Command

Department of the Navy

Attn: Code ORD 033

Washington, D. C. 20360

Commanding officer

Naval Air Development Center

Aeronautical Materials Div.

Johnsville

Attn: Code MAM

Warminster, Pa. 18974

Commanding officer

Naval Ordnance Laboratory

Attn: Code 210

White Oak

Silver Spring, Maryland 20910

Commander

Naval Ship Systems Command

Department of the Navy

Attn: Code 0342

Washington, D. C. 20360

Commanding officer

Naval Civil Engineering Laboratory

Attn: Code L70

Port Hueneme, California 93041

Commander

Naval Ship Engineering Center

Department of the Navy

Attn: Code 6101

Washington, D. C. 20360
Naval Ships R\&D Laboratory

Annapolis Division

Attn: Code $\mathrm{A} 800$

Annapolis, Maryland 21402

Commanding officer

Naval Ships R\&D Center

Attn: Code 747

Washington, D. C. 20007

U. S. Naval Postgraduate School

Attn: Department of Chemistry and Material Science

Monterey, California 93940

Commander Naval Weapons Center

Naval Weapons Center

Attn: Code 5560

China Lake, California 93555

Commander

Naval Underseas Warfare Center

Pasadena, California 92152

Scientific Advisor

Commandant of the Marine Corps

Attn: Code AX

Washington, D. C. 20380

Commanding officer

Army Research Office, Durham

Box CM, Duke Station

Attn: Metallurgy \& Ceramics Div.

Durham, North Carolina 27706

Office of Scientific Research

Department of the Air Force

Attn: Solid state Div. (SRPS)

Washington, D. C. 20333

Defense Documentation Center Cameron Station

Alexandria, Virginia 22314 
National Bureau of Standards

Attn: Metallurgy Division

Washington, D. C. 20234

National Bureau of Standards

Attn: Inorganic Materials Div.

Washington, D. C. 20234

Atomic Energy Commission

Attn: Metals \& Materials Branch

Washington, D. C. 20545

Argonne National Laboratory

Metallurgy Division

P. O. Box 299

Lemont, Illinois 60439

Brookhaven National Laboratory

Technical Information Division

Attn: Research Library

Upton, Long Island, New York 11973

\section{Library}

Bldg. 50, Room 134

Lawrence Radiation Laboratory

Berkeley, California 94720

Los Alamos Scientific Laboratory

P. O. Box 1663

Attn: Report Librarian

Los Alamos, New Mexico 87544

Commanding officer

Army Materials and Mechanics

Research Center

Attn: Res. Programs Office (AMXMR-P)

Watertown, Massachusetts 02172

\section{Director}

Metals \& Ceramics Division

Oak Ridge National Laboratory

P. O. Box X

Oak Ridge, Tennessee 37830

Commanding officer

Naval Underwater Systems Center Newport, Rhode Island 02844
Aerospace Research Laboratories Wright-Patterson AFB

Building 450

Dayton, Ohio 45433

Defense Metals Information Center Battelle Memorial Institute 505 King Avenue

Columbus, Ohio 43201

Army Electronics Command

Evans Signal Laboratory

Solid State Devices Branch

c/o Senior Navy Liaison Officer

Fort Monmouth, New Jersey 07703

Commanding General

Department of the Army

Frankford Arsenal

Attn: ORDBA-1320, 64-4

Philadelphia, Pennsylvania 19137

Executive Director

Materials Advisory Board

National Academy of Sciences

2101 Constitution Avenue, N. W.

Washington, D. C. 20418

NASA Headquarters

Attn: Code RRM

Washington, D. C. 20546

Air Force Materials Lab

Wright-Patterson AFB

Attn: MAMC

Dayton, Ohio 45433

Air Force Materials Lab

Wright-Patterson AFB

Attn: MAAM

Dayton, Ohio 45433

Deep Submergence Systems Project

Attn: DSSP-00111

Washington, D. C. 20360 
Advanced Research Projects Agency

Attn: Director, Materials Science Washington, D. C. 20301

Army Research Office

Attn: Dr. T. E. Sullivan

3045 Columbia Pike

Arlington, Virginia 22204

Department of the Interior

Bureau of Mines

Attn: Science \& Engineering Advisor

Washington, D. C. 20240

Defense Ceramics Information Center

Battelle Memorial Institute

505 King Avenue

Columbus, Ohio 43201

National Aeronautics \& Space Adm.

Lewis Research Center

Attn: Librarian

21000 Brookpark Rd.

Cleveland, Ohio 44135

Naval Missile Center

Materials Consultant

Code 3312-1

Point Mugu, California 93041

Commanding officer

Naval Weapons Center Corona Labs.

Corona, California 91720

Commander

Naval Air Test Center

Weapons systems Test Div. (Code OlA)

Patuxent River, Maryland 20670

Director

Ordnance Research Laboratory

P. O. Box 30

State College, Pennsylvania 16801
Director

Applied Physics Laboratory

Johns Hopkins University

8621 Georgia Avenue

Silver Spring, Maryland 20901

Director

Applied Physics Laboratory

1013 Northeast Fortieth St.

Seattle, Washington 98105

Materials Sciences Group

Code S130.1

271 Catalina Boulevard

Navy Electronics Laboratory

San Diego, California 92152

Dr. Waldo K. Lyon

Director, Arctic Submarine Laboratory

Code 90, Building 371

Naval Undersea R\&D Center

San Diego, California 92132

Dr. R. Nathan Katz

Ceramics Division

U.S. Army Materials \& Mechanics

Research Center

Watertown, Mass. 02172

Lt. Cmar. D. N. Hull

Chesapeake Division

Naval Facilities Engineering Command

Washington, D.C. 20390

Dr. John Norbutas

Code L63

Naval Civil Engineering Laboratory

Port Hueneme, Calif. 93043

Mr. Herbert C. Lamb

Naval Facilities Engineering Command Code 032E

200 stovall st.

Alexandria, Va. 22332

Dr. M. Yachnis

Naval Facilities Engineering Command Code 04B

200 Stovall St.

Alexandria, Va. 22332 
Professor R. Roy

Materials Research Laboratory

Pennsylvania State University

University Park, Pennsylvania 16802

Professor D. H. Whitmore

Department of Metallurgy

Northwestern University

Evanston, Illinois 60201

Professor J. A. Pask

Department of Mineral Technology

University of California

Berkeley, California 94720

Professor D. Turnbull

Div. of Engineering and Applied sci.

Harvard University

Pierce Hall

Cambridge, Massachusetts 02100

Dr. T. Vasilos

AVCO Corporation

Research and Advanced Development Div. 201 Lowell st.

Wilmington, Massachusetts 01887

Dr. H. A. Perry

Naval Ordnance Laboratory

Code 230

Silver spring, Maryland 20910

Dr. Paul Smith

Crystals Branch, Code 6430

Naval Research Laboratory

Washington, D. C. 20390

Dr. A. R. C. Westwood

RIAS Division

Martin-Marietta Corporation

1450 South Rolling Road

Baltimore, Maryland 21227

Dr. W. Haller

Chief, Inorganic Glass Section

National Bureau of Standards

Washington, D. C. 20234
Dr. R. H. Doremus

General Electric Corporation

Metallurgy and Ceramics Lab.

Schenectady, New York 12301

Professor G. R. Miller

Department of Ceramic Engineering

University of Utah

Salt Lake City, Utah 84112

Dr. Philip L. Farnsworth

Materials Department

Battelle Northwest

P. O. Box 999

Richland, Washington 99352

Mr. G. H. Heartling

Ceramic Division

Sandia Corporation

Albuquerque, New Mexico 87101

Mr. I . Berman

Army Materials and Mechanics

Research Center

Watertown, Massachusetts 02171

Dr. F. F. Lange

Westinghouse Electric Corporation

Research Laboratories

Pittsburgh, Pennsylvania 15235

Professor H. A. Mckinstry

Pennsylvania State University

Materials Research Laboratory

University Park, Pa. 16802

Professor T. A. Litovitz

Physics Department

Catholic University of America

Washington, D. C. 20017

Dr. R. J. Stokes

Honeywell Corporate Research Center

10701 Lyndale Avenue South

Bloomington, Minnesota 55420 
Dr. Harold Liebowitz

Dean of Engineering

George Washington Univeristy

Washington, D. C. 20006

Dr. H. Kirchner

Ceramic Finishing Company

P. O. Box 498

State College, Pennsylvania 16801

Professor A. H. Heuer

Case Western Reserve University

University Circle

Cleveland, Ohio 44106

Dr. D. E. Niesz

Battelle Memorial Institue

505 King Avenue

Columbus, Ohio 43201

Dr. F. A. Kroger

University of Southern California

University Park

Los Angeles, California 90007

Dr. Sheldon M. Wiederhorn

National Bureau of Standards

Inorganic Materials Division

Washington, D. C. 20234

Dr. C. O. Hulse

United Aircraft Research Labs

United Aircraft Corporation

East Hartford, Connecticut 06108

Professor M. H. Manghnani

University of Hawaii

Hawaii Institute of Geophysics

2525 Correa Road

Honolulu, Hawaii 96822

Dr. Stephen Malkin

Department of Mechanical Engineering University of Texas

Austin, Texas 78712

Prof. H. E. Wilhelm

Department of Mechanical Engineering

Colorado State University

Fort Collins, Colorado 80521
Stanford University

Dept. of Materials Sciences

Stanford, California 94305

Dr. R. K. MacCrone

Department of Materials Engineering

Rensselaer Polytechnic Institute

Troy, New York 12181

Dr. D. C. Mattis

Belfer Graduate School of Science

Yeshiva University

New York, New York 10033

Professor R. B. Williamson

College of Engineering

university of California

Berkeley, California 94720

Professor R.. W. Gould

Department of Metallurgical

and Materials Engineering

College of Engineering

University of Elorida

Gainesville, Florida 32601

Professor V. S. Stubican

Department of Materials Science

Ceramic Science section

Pennsylvania State University

University Park, Pennsylvania

16802

Dr. R. C. Anderson

General Electric R\&D Center

P. O. Box 8

Schenectady, New York 12301

Dr. Bert Zauderer

MHD Program, Advanced Studies

Room L-9513-VFSC

General Electric Company

P. O. Box 8555

Philadelphia, Pennsylvania 19101

Prof. C. F. Fisher, Jr.

Department of Mechanical and Aero-

space Engineering

University of Tennessee

Knoxville, Tennessee 37916 


\begin{tabular}{|c|c|c|}
\hline $\begin{array}{l}\text { 1. PUBLICATION OR REPORT NO. } \\
\text { NBSIR } 74-512\end{array}$ & $\begin{array}{l}\text { 2. Gov't Accession } \\
\text { No. }\end{array}$ & 3. Recipient's Accession No. \\
\hline \multirow{2}{*}{\multicolumn{2}{|c|}{$\begin{array}{l}\text { 4. TITLE AND SUBTITLE } \\
\text { The Proof Testing of Porcelain Insulators and the } \\
\text { Application of Acoustic Emission }\end{array}$}} & \multirow{2}{*}{$\begin{array}{l}\text { 5. Publication Date } \\
\text { June } 1974 \\
\text { 6. Performing Organization Code }\end{array}$} \\
\hline & & \\
\hline $\begin{array}{l}\text { 7. AUTHOR(S) } \\
\text { A. G. Evans, S. M. Wiederhorn, M. Linzer, and }\end{array}$ & R. Fuller, Jr. & $\begin{array}{l}\text { 8. Performing Organ. Report No. } \\
\text { NBSIR 74-512 }\end{array}$ \\
\hline \multicolumn{2}{|l|}{$\begin{array}{l}\text { 9. PERFORMING ORGANIZATION NAME AND ADDRESS } \\
\text { NATIONAL BUREAU OF STANDARDS } \\
\text { DEPARTMENT OF COMMERCE } \\
\text { WASHINGTON, D.C. } 20234\end{array}$} & $\begin{array}{l}\text { 10. Project/Task/Work Unit No. } \\
3130451 \\
\text { 11. Contract/Grant No. } \\
\text { PO-3-0072 }\end{array}$ \\
\hline \multirow{2}{*}{\multicolumn{2}{|c|}{$\begin{array}{l}\text { 12. Sponsoring Organization Name and Complete Address (Street, City, State, ZIP) } \\
\text { Naval Civil Engineering Laboratory } \\
\text { Port Hueneme, California. } 93043\end{array}$}} & $\begin{array}{l}\text { 13. Type of Report \& Period } \\
\text { Covered } \\
\text { Final Report }\end{array}$ \\
\hline & & 14. Sponsoring Agency Code \\
\hline
\end{tabular}

\section{SUPPLEMENTARY NOTES}

To be published in the Journal of The American Ceramic Society

16. ABSTRACT (A 200-word or less factual summary of most significant information. If document includes a significant bibliography or literature survey, mention it here.)

An investigation of proof testing has been conducted on large cone and post porcelain insulators. The cone configuration was found to be unsuitable for overload proof testing to the loads needed for effective lifetime predictions. The only merit of subjecting this configuration to a proof test is the assurance of no immediate macrocracking during installation. This is achieved by testing to a load marginally larger than the service load. Conversely, the post configuration was found to exhibit the basic prerequisites for effective proof testing; but detailed stress analysis of this system is needed before specific proof testing procedures can be recommended. Finally, acoustic emission measurements were found to be a major asset for monitoring both macrocracking events and stress development during the proof tests.

17. KEY WORDS (six to twelve entries; alphabetical order; capitalize only the first letter of the first key word unless a proper name; separated by semicolons)

Acoustic emission; macrocracking; porcelain insulators; proof testing; residual strain.

18. AVAILABILITY

[ Unlimited

X. For Official Distribution. Do Not Release to NTIS

Order From Sup. of Doc., U.S. Government Printing Office

Washington, D.C. 20402, SD Cat. No. C13

Order From National Technical Information Service (NTIS) Springfield, Virginia 22151

\begin{tabular}{|l|c|}
\hline $\begin{array}{l}\text { 19. SECURITY CLASS } \\
\text { (THIS REPURT) }\end{array}$ & 21. NO. OF PAGES \\
UNCL ASSIFIED & 42 \\
\hline $\begin{array}{l}\text { 20. SECURITY CLASS } \\
\text { (THIS PAGE) }\end{array}$ & 22. Price \\
UNCLASSIFIED & \\
\hline
\end{tabular}

